\title{
A toolkit for developing bilingual lexicons for international HIV prevention clinical trials
}

Catalina B. Ramirez

Natasha Mack

Barbara Friedland

Population Council

Follow this and additional works at: https://knowledgecommons.popcouncil.org/departments_sbsr-hiv

Part of the Demography, Population, and Ecology Commons, Family, Life Course, and Society Commons, International Public Health Commons, and the Medicine and Health Commons How does access to this work benefit you? Let us know!

\section{Recommended Citation}

Ramirez, Catalina B., Natasha Mack, and Barbara Friedland. 2013. "A toolkit for developing bilingual lexicons for international HIV prevention clinical trials." New York: Population Council and FHI 360. 


\section{A TOOLKIT FOR DEVELOPING BILINGUAL LEXICONS FOR INTERNATIONAL HIV PREVENTION CLINICAL TRIALS}

CATALINA RAMIREZ, MPH, MHA NATASHA MACK, PHD BARBARA FRIEDLAND, MPH 



\section{A TOOLKIT FOR DEVELOPING BILINGUAL LEXICONS FOR INTERNATIONAL HIV PREVENTION CLINICAL TRIALS}

Catalina Ramirez, MPH, MHA

Natasha Mack, PhD

Barbara Friedland, MPH 


\section{ACKNOWLEDGMENTS}

The authors wish to thank Kate MacQueen, PhD, along with Soori Nnko, PhD, the National Institute for Medical Research (NIMR), Tanzania, Kellly Simpson, and the participants of the study from which the toolkit was developed. We also express our appreciation to Janet Kariuki and Stella Mujaya for their assistance with Swahili translations. In addition, the authors are grateful to Joyce Altman, Sherry Hutchinson, Virginia Kallianes, and Christina Tse for their assistance on this publication.

Suggested citation: Ramirez, Catalina, Natasha Mack, and Barbara Friedland. 2013. A Toolkit for Developing Bilingual Lexicons for International HIV Prevention Clinical Trials. New York: Population Council and FHI 360.

This toolkit was made possible through support provided by the United States Agency for International Development (USAID) under the terms of Cooperative Agreement No. HRN-A-00-99-00010. The contents are the responsibility of the authors and do not necessarily reflect the views of USAID or the United States Government.

\section{(2) Population Council}

The Population Council confronts critical health and development issues-from stopping the spread of HIV to improving reproductive health and ensuring that young people lead full and productive lives. Through biomedical, social science, and public health research in 50 countries, we work with our partners to deliver solutions that lead to more effective policies, programs, and technologies that improve lives around the world. Established in 1952 and headquartered in New York, the Council is a nongovernmental, nonprofit organization governed by an international board of trustees.

One Dag Hammarskjold Plaza

New York, New York 10017 USA

Tel: 1-212-339-0500/Fax: 1-212-755-6052

www.popcouncil.org fhi 360

FHI 360 is a nonprofit human development organization dedicated to improving lives in lasting ways by advancing integrated, locally driven solutions. Our staff includes experts in health, education, nutrition, environment, economic development, civil society, gender equality, youth, research, technology, and communication and social marketing - creating a unique mix of capabilities to address today's interrelated development challenges. FHI 360 serves more than 60 countries and all U.S. states and territories.

2224 East NC Highway 54

Durham, NC 27713 USA

Tel: 1-919-544-7040/Fax: 1-919-544-7261

www.fhi360.org

C2013 The Population Council, Inc.

Any part of this publication may be photocopied without permission from the publisher provided that copies are distributed without charge and that full source citation is provided. The Population Council and FHI 360 would appreciate receiving a copy of any materials in which the text is used. 


\section{TABLE OF CONTENTS}

ACKNOWLEDGMENTS $\quad$ ii

LIST OF EXAMPLES, FIGURES, AND TABLES iv

ACRONYMS V v

I. INTRODUCTION 1

What Is a Bilingual Lexicon? 1

Why Is a Bilingual Lexicon Useful?

Why Use This Toolkit? 3

II. THE LEXICON DEVELOPMENT PROCESS 4

Getting Started 4

Step 1: Develop Preliminary Lexicon 4

Step 2: Develop Focus Group Discussion (FGD) Guide to Assess the Preliminary Lexicon 6

Step 3: Analyze Data from Development FGDs 12

Step 4: Revise the Preliminary Research Lexicon 14

Step 5: Develop FGD Guides to Assess the Revised Lexicon 16

Step 6: Analyze Data from Verification FGDs 21

Step 7: Finalize the Research Lexicon $\quad 24$

$\begin{array}{ll}\text { III. LEXICON DATABASE } & 28\end{array}$

APPENDIX 1. PRE-RESEARCH ACTIVITIES 29

APPENDIX 2. CASE STUDIES 32

APPENDIX 3. LEXICON EXAMPLE (SWAHILI) 44

APPENDIX 4. LEXICON DATABASE SAMPLE SCREENS 59 


\section{LIST OF EXAMPLES, FIGURES, AND TABLES}

\section{EXAMPLES}

Example 1 Excerpt from Bilingual Lexicon in English and Zulu,

Carraguard Phase 3 Trial, KwaZulu-Natal, South Africa

Example 2 Identifying Terms in an Informed Consent Form

Example 3 Preliminary Lexicon Development Spreadsheet (Swahili)

Example 4 Focus Group Discussion Guide

Example 5 Revised Preliminary Lexicon Spreadsheet (Swahili)

Example 6 Verbal Multiple-Choice Data Collection Form (Swahili)

Example 7 Data Collected from Verbal Multiple Choice Technique

During FGDs

Example 8 Revised Lexicon Spreadsheet (Swahili)

25

Example 9 Final Lexicon Entry (Swahili)

\section{FIGURES}

Figure 1 Research Lexicon Process 3

Figure 2 Research Lexicon Process $\quad 24$

Figure 3 Research Staff Organization Chart 29

\section{TABLES}

Table 1 Questioning Techniques to Assess Preliminary Lexicon 7

Table 2 Questioning Techniques to Assess Revised Lexicon 


\section{ACRONYMS}

AIDS

ARV

FGD

FTE

HIV

PI

PrEP

RA

STD acquired immunodeficiency syndrome

antiretroviral

focus group discussion

full-time effort

human immunodeficiency virus

Principal Investigator

pre-exposure prophylaxis

Research Assistant

sexually transmitted disease 
vi - A Toolkit for Developing Bilingual Lexicons for International HIV Prevention Clinical Trials 


\section{INTRODUCTION}

Achieving participant comprehension is one of the most difficult practical, ethical, and regulatory aspects of clinical research, even under optimal conditions where trial volunteers are well-educated and familiar with Western medical practice and research. Language can be a barrier to participant comprehension in any setting, because researchers often use technical terminology that trial participants may not easily understand.

In the context of international clinical trials, language and communication poses additional challenges when local languages do not have scientific or technical vocabularies in relevant subject areas. When new vocabulary is needed for terms that do not exist in the local language (e.g., "placebo," "randomization," or "microbicide"), researchers and translators develop specific translations for use in the studies they are conducting. No standardized process exists, however, for developing a set of agreed upon terms, definitions, and translations in local languages that ensures participants understand both technical and nontechnical terms used in the clinical trial context.

Effectively informing research participants is particularly complicated in HIV prevention trials that involve HIV-negative volunteers at high risk of HIV infection, who are often from low-literacy, resource-poor communities. In addition, HIV prevention trials deal with a disease that is stigmatized and with sexual behaviors that may not be openly discussed. Terms related to sexual behaviors (e.g., "anal sex," "oral sex," "steady partner," "casual partner") and reproductive health likely exist in local languages; however, care must be taken in the selection of words to ensure terms are appropriate for use in the context of a clinical trial and understandable but not offensive or pejorative.

Because there is no standardized process for translation across research sites, study terminology may gain only limited usage, requiring researchers to re-translate terms for each study. The lack of a standardized process can make it difficult for researchers to decide which words to use, or even to find out what terminology choices exist, because published resources may not be available. As a result, it is less likely that clinical trial vocabulary developed for a particular language will gain currency, and therefore, the opportunity for this new "lexicon" to achieve longevity is weakened. The lack of consistent translations hinders access to scientific and technical knowledge for clinical trial participants, as well as for research communities, at large.

\section{What Is a Bilingual Lexicon?}

A lexicon is a set of terms, similar to a glossary, relating specifically to a particular subject area-in this case clinical trials of HIV prevention technologies. The bilingual lexicon is used to ensure consistency in translation across all documents and materials used in a particular clinical trial. Thus, once the bilingual lexicon has been developed, there is a standard way to translate terms used in informed consent forms, data collection instruments, counseling sessions, and communication about the trial in the community. Example 1 shows a sample of a bilingual lexicon in English and Zulu. 


\begin{tabular}{|c|c|c|c|c|}
\hline Term & English Definition & $\begin{array}{l}\text { Translation into } \\
\text { Local Language }\end{array}$ & $\begin{array}{l}\text { Definition in Local } \\
\text { Language }\end{array}$ & $\begin{array}{l}\text { Back } \\
\text { Translation }\end{array}$ \\
\hline Abnormal results & $\begin{array}{l}\text { Information from tests } \\
\text { that show there is } \\
\text { an infection or other } \\
\text { condition that is } \\
\text { unusual for a person }\end{array}$ & $\begin{array}{l}\text { Imiphumela } \\
\text { engajwayelekile }\end{array}$ & $\begin{array}{l}\text { Ulwazi oluqhamuka } \\
\text { ekuhloleni olutshengisa } \\
\text { ukuthi kunokutheleleka } \\
\text { noma esinye isimo } \\
\text { esingajwayelekile } \\
\text { kumuntu }\end{array}$ & $\begin{array}{l}\text { Abnormal } \\
\text { results }\end{array}$ \\
\hline Abnormalities & $\begin{array}{l}\text { Any condition that } \\
\text { is unusual for a } \\
\text { person-signs (seen by } \\
\text { clinician), symptoms } \\
\text { (experienced by } \\
\text { woman) }\end{array}$ & Okungajwayelekile & $\begin{array}{l}\text { Noma isiphi isimo } \\
\text { esingajwayelekile } \\
\text { kumuntu-izimpawu } \\
\text { (ezibonwa udokotela), } \\
\text { izinkomba (ezizwiwa } \\
\text { owesifazane) }\end{array}$ & Abnormalities \\
\hline Abstinent(ence) & $\begin{array}{l}\text { Not having sex (for a } \\
\text { period of time) }\end{array}$ & $\begin{array}{l}\text { Ukungalwenzi } \\
\text { ucansi }\end{array}$ & $\begin{array}{l}\text { Ukungalwenzi ucansi } \\
\text { (isikhathi esithile) }\end{array}$ & Abstain \\
\hline AIDS & $\begin{array}{l}\text { Condition caused by } \\
\text { HIV that prevents the } \\
\text { body from fighting } \\
\text { disease }\end{array}$ & Isifo sengculaza & $\begin{array}{l}\text { Izifo eziningi ezibangelwa } \\
\text { igciwane lengculaza } \\
\text { elenza ukuba umzimba } \\
\text { womuntu ungakwazi } \\
\text { ukuzisebenzela } \\
\text { ngokwawo ngenxa } \\
\text { yokuthi libulala } \\
\text { amasosha omzimba } \\
\text { omuntu ekumele alwe } \\
\text { nezifo }\end{array}$ & AIDS \\
\hline Anal sex & $\begin{array}{l}\text { Sex with penis in } \\
\text { woman's anus }\end{array}$ & $\begin{array}{l}\text { Ucansi Iwembobo } \\
\text { yangemuva }\end{array}$ & $\begin{array}{l}\text { Ukufaka isitho } \\
\text { sangasese sowesilisa } \\
\text { embobeni yokuzithuma } \\
\text { yowesifazane }\end{array}$ & Anal sex \\
\hline
\end{tabular}

"Skoler-Karpoff, S. et al. 2008. "Efficacy of Carraguard for prevention of HIV infection in women in South Africa: a randomised, double-blind, placebo-controlled trial," The Lancet 372(9654): 1977-1987.

\section{Why Is a Bilingual Lexicon Useful?}

Overcoming translation challenges is vital for producing bilingual glossaries that can be used to translate technical information, be disseminated among developing country populations and trial researchers, and presumably improve participant comprehension of clinical trial documents. Correct translations are also critical to be certain that trial participants understand questions they are asked and answer them appropriately. For example, in a recent microbicide clinical trial, participants were asked if they had had unprotected anal intercourse. The frequency of "yes" responses among Zulu speakers was higher than at sites where other languages were spoken, leading investigators to question the translation. The translation of "anal sex" was euphemistic, and local clinical trial staff thought the translated term might have been erroneously interpreted by study participants as vaginal "sex from behind." In another trial, results of pilot-testing the informed consent form indicated that people understood the word "care" to mean "cure," because of an inaccurate translation. Thus, it is crucial to ensure correct and appropriate translations throughout all trial materials. 


\section{Why Use This Toolkit?}

This toolkit will guide researchers through the process for identifying or improving translations of clinical research terms that are difficult to translate or comprehend. The toolkit provides a multistep process for eliciting and field-testing culturally and linguistically valid translations of key research-related terms and concepts.

The process, which is outlined in detail in this toolkit, involves several steps:

- Developing a preliminary lexicon: A preliminary lexicon includes two entries: 1) an English entry with the words or terms to be translated, as well as simple definitions, and 2) a local language entry that includes a translation of the English term and simple definition.

- Revising and refining the lexicon: A first round of focus groups that utilizes several questioning techniques will provide insight into local participants' baseline understanding of terms and translated definitions. Based on the participant discussion, the local language entry for the research lexicon will be refined or additional data collection will be conducted with different techniques to better assess participant understanding of the research term or of a revised definition.

- Verifying the revised lexicon: In cases where a questioning technique was successful a second round of focus groups will allow you to verify the terms that were elicited in the first round and assess whether participants prefer one term over another. In cases where a questioning technique was not successful a second round focus will allow you to test an existing or revised term definition.

- Finalizing the lexicon: The lexicon development process allows for as many rounds of focus groups and revisions of the preliminary lexicon as necessary. Once all revised terms have been successfully verified and/or you have identified term preferences, then the locallanguage entry for the research lexicon can be finalized.

Figure 1 Research Lexicon Process

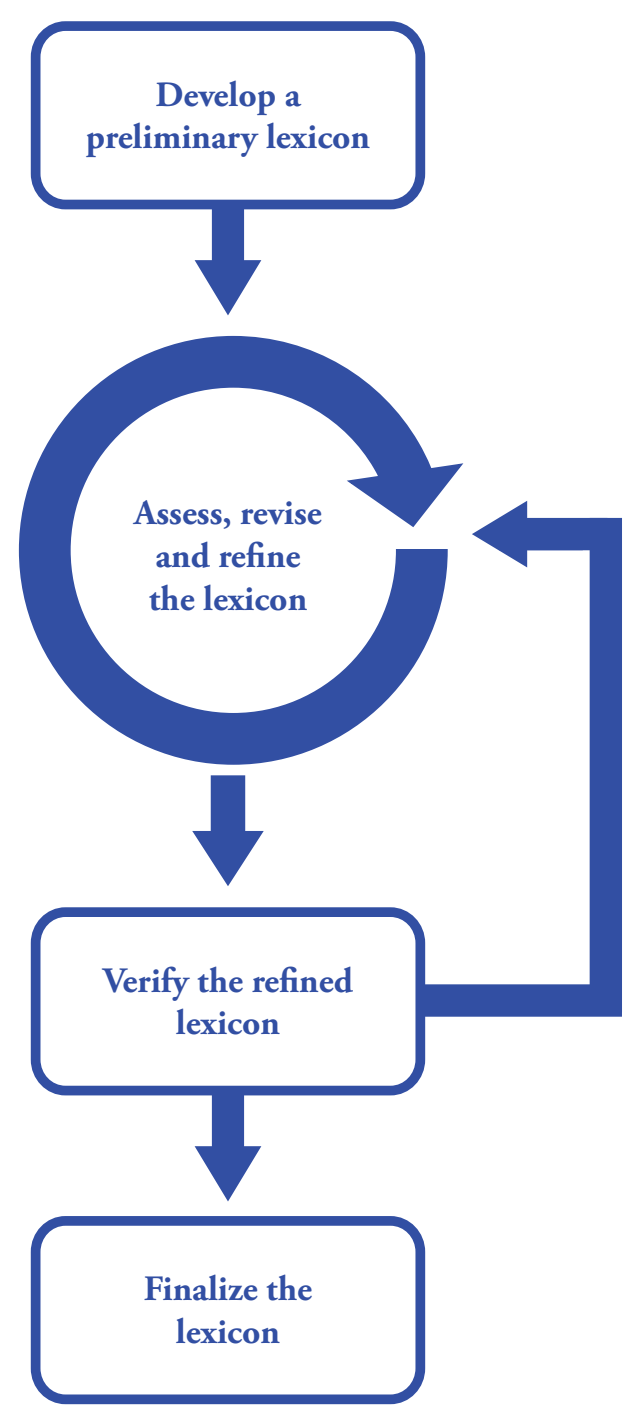




\section{THE LEXICON DEVELOPMENT PROCESS}

\section{Getting Started}

Before initiating any research activities, it is important to meet with the local research team and confirm that adequate human, financial, and time resources are available to complete data collection and analysis (see Appendix 1 for a thorough outline of pre-research activities).

The next few sections will guide you through the process of identifying culturally relevant translations for potentially difficult-to-comprehend terminology related to research, sexual behavior, reproductive health, and infectious diseases commonly used in HIV prevention clinical trials. This process will entail developing "translatable" definitions for each term with the help of a local translator, conducting focus groups to elicit local terminology, verifying the comprehensibility of definitions, and analyzing the data to identify participants' preferred translations.

\section{Step 1: Develop Preliminary Lexicon}

In collaboration with site investigators and a qualified local translator, develop an English lexicon of terms used in the clinical trial documents which you assess as potentially problematic when translated into the local language. If informed consent forms have already been developed, it is useful to begin by reviewing these documents and identifying specific research terms or explanations of the research that may be unfamiliar to the local population (see Example 2). 


\section{Example 2 Identifying Terms in an Informed Consent Form}

\section{Enhancing Local Verbal and Nonverbal Communication for Informed Consent Processes in Tanzania MOCK INFORMED CONSENT-NOT A REAL STUDY}

\section{Introduction}

The purpose of today's enrollment visit is to explain all the details of the HIV-PrEP clinical trial to you, answer any questions that you may have, review your eligibility to take part in the trial, obtain your consent to take part in the trial, and enroll you in the research study.

In order to be sure that you are informed about being in this HIV-PrEP clinical trial, we are asking you to read (or have read to you) this Consent Form in Swahili. At the end of the consent form, we will ask you to indicate your willingness to join in this trial. This consent form may contain some words that are unfamiliar to you. Please ask us to explain anything that you do not understand.

\section{Information about HIV and How to Protect Oneself from Getting HIV}

HIV is the virus that causes AIDS. There is no cure for HIV. In sub-Saharan Africa, and here in Tanzania, the main way HIV is spread is through sex. If a person has more than one sex partner, they are more likely to become infected with HIV. Anal sex has a much higher risk of getting a person infected than vaginal sex. The best way to prevent HIV is not having sex. If a person has sex, their risk of becoming infected with HIV is smaller if condoms are used every time they have sex. Condoms are $80 \%$ to $90 \%$ effective in protecting a person against HIV if used correctly every time they have sex. At every study visit during this trial, you will be given as many free condoms as you need. We will teach you how to use the condoms. Also, as part of this trial, we will talk with you about your sex behavior and help you decide what you can do to reduce your risk of getting HIV.

\section{Reason for Being Asked to Take Part in the Research}

You are being asked to take part in this clinical trial because you are a woman who is sexually active and may be at increased risk of HIV exposure. During the trial, you believe that you will continue to be sexually active for the next 12 months. You can still stay in the trial if you change your sexual behavior.

\section{General Information about the HIV-PrEP Clinical trial}

We are conducting this clinical trial to find out if PrevVI is safe and can reduce the chance that women get HIV from sex. PrevVI is a pill that needs to be taken once a day, with or without food. It is made from two different types of antiretroviral drugs (also called ARVs). ARVs are used to treat people with HIV.

PrevVI is used to treat people already infected with HIV. We do not know if it can also prevent people from getting infected with HIV. The purpose of this clinical trial is to find out if PrevVI can be used to prevent HIV.

In this trial, women will be assigned to one of two groups by chance. There is an equal chance of being in either of the groups. No one will choose which group they join. One group will be given PrevVl. The other group will be given a placebo. The placebo is a harmless pill that looks, tastes, and is the same size as PrevVl but contains no active ingredients. The placebo does not contain PrevVl. We know for certain that the placebo does not protect against HIV. We do not know if PrevVI protects against HIV. That is why we are doing this clinical trial.

During the trial, neither the women nor study staff will know who gets PrevVI and who gets the placebo. This will be known only at the end of the trial. Researchers will then compare how many women in each group became infected with HIV. That is how we can find out whether or not PrevVI can reduce the chance that women get HIV through sex. 
Once you have identified the terms, enter them into a spreadsheet, develop simple, nontechnical definitions for each word in English, and document the source of the definition (see Example 3).

Once the English terms and definitions have been entered into the lexicon, work with the qualified local translator to ascertain which words have an equivalent term in the target language. For terms that do not have an equivalent, work with the translator to identify potential translation choices. Document his/her preferred choice along with the reason for his/her preference.

Example 3 Preliminary Lexicon Development Spreadsheet (Swahili)

\begin{tabular}{|l|l|l|l|}
\hline \multicolumn{2}{|l|}{ Term (English) } & English Definition & $\begin{array}{l}\text { Translation of Definition } \\
\text { (Target Language) }\end{array}$ \\
\hline $\begin{array}{l}\text { Casual sexual } \\
\text { partner }\end{array}$ & $\begin{array}{l}\text { A lover a person has sex with } \\
\text { occasionally }\end{array}$ & $\begin{array}{l}\text { Mtu ambaye anakutana naye } \\
\text { kimapenzi mara chache }\end{array}$ & Translator/PI \\
\hline Enroll & $\begin{array}{l}\text { Process of registering to be an } \\
\text { official member of the study } \\
\text { participants }\end{array}$ & $\begin{array}{l}\text { Kujiandikisha na kuwa mmoja wa } \\
\text { washiriki rasmi wa utafiti }\end{array}$ & Translator/PI \\
\hline Side effects & $\begin{array}{l}\text { Unwanted problems that result } \\
\text { from taking a drug }\end{array}$ & $\begin{array}{l}\text { Matatizo yasiyokusudiwa } \\
\text { yanayotokana na utumiaji wa } \\
\text { dawa }\end{array}$ & Translator/PI \\
\hline Speculum & $\begin{array}{l}\text { An instrument to view the } \\
\text { vagina }\end{array}$ & $\begin{array}{l}\text { Kifaa kinachotumika kufungua } \\
\text { njia ya uke }\end{array}$ & Translator/PI \\
\hline
\end{tabular}

\section{Step 2: Develop Focus Group Discussion (FGD) Guide to Assess the Preliminary Lexicon}

Now, you will need to develop a data collection guide that will assess your preliminary bilingual lexicon among participants from the target population for the trial.

\section{Identifying the correct questioning technique}

Four questioning techniques are explained below and examples for each one are provided. Choosing the correct questioning technique is a critical step in the process because it will dictate the type of information you will be able to collect from participants and later use to revise your research lexicon. 
Table 1 Questioning Techniques to Assess Preliminary Lexicon

\begin{tabular}{|c|c|c|}
\hline Technique & Description & Data Collected in Round 1 \\
\hline $\begin{array}{l}\text { Term } \\
\text { Explanation }\end{array}$ & $\begin{array}{l}\text { Tests whether participants are familiar with } \\
\text { technical and nontechnical terms that have } \\
\text { been translated by providing the translated } \\
\text { terms and asking participants to explain them } \\
\text { to the group. }\end{array}$ & $\begin{array}{l}\text { - Insight on participant familiarity } \\
\text { with technical and nontechnical } \\
\text { terms, in target language. } \\
\text { - List of technical and nontechnical } \\
\text { terms, in target language. }\end{array}$ \\
\hline $\begin{array}{l}\text { Definition } \\
\text { Explanation }\end{array}$ & $\begin{array}{l}\text { Tests a definition that has been developed } \\
\text { by providing participants with a term and } \\
\text { its definition and then asking them to } \\
\text { explain the term (in their own words) to the } \\
\text { group, or answer questions that assess their } \\
\text { understanding of the concept. }\end{array}$ & $\begin{array}{l}\text { - Feedback on translated definition } \\
\text { (i.e., words or concepts that are } \\
\text { difficult to understand). } \\
\text { - List of technical and nontechnical } \\
\text { terms, in target language. }\end{array}$ \\
\hline $\begin{array}{l}\text { Term } \\
\text { Elicitation }\end{array}$ & $\begin{array}{l}\text { Identifies whether participants are familiar } \\
\text { with an existing term or concept by providing } \\
\text { them with the translatable definition that } \\
\text { you developed and asking them to provide } \\
\text { matching terms. In some cases, you may } \\
\text { also use scenarios to identify terms that are } \\
\text { appropriate in a specific context (i.e., doctor's } \\
\text { office, among peers). }\end{array}$ & $\begin{array}{l}\text { - List of technical and nontechnical } \\
\text { terms, in target language. } \\
\text { - Feedback on explanation of term } \\
\text { (i.e., words or concepts that are } \\
\text { difficult to understand). }\end{array}$ \\
\hline $\begin{array}{l}\text { Term } \\
\text { Creation }\end{array}$ & $\begin{array}{l}\text { Gathers participants' ideas about how to } \\
\text { translate relatively new English scientific words } \\
\text { that have no equivalents in the target language } \\
\text { by providing them with a detailed explanation } \\
\text { of the idea, object, or process. Asks } \\
\text { participants to reiterate their understanding of } \\
\text { the concept and then provide terms or phrases } \\
\text { in the target language that could be used to } \\
\text { describe the concept. }\end{array}$ & $\begin{array}{l}\text { - New terms created by participants. } \\
\text { - Feedback on terms that were pro- } \\
\text { vided to participants. }\end{array}$ \\
\hline
\end{tabular}

\section{Term Explanation Technique}

The Term Explanation Technique is effective for assessing participants' familiarity with existing technical terms. To use this technique, provide participants with the translated term and ask them to explain the meaning, or provide participants with an explanation of the term and then ask them to explain it to the group.

\section{Term: Safe Sex}

Question: What do you think is meant by the expression "safe sex"?

Term: Sexually Transmitted Infection

Question: Sexually transmitted infections happen when a person has physical contact with the penis, vagina, or anus of a person who has an infection, even if they do not have symptoms. Anyone can get a sexually transmitted infection. What are the different kinds of sexually transmitted infections? What are the symptoms of these infections? 
Term: Research Study

Question: Research is the process of carefully studying information to discover one or more facts. Let me give you an example. Scientists have developed a new drug. They want to know if it will cure malaria infection within one week. They must do research to learn the answer to this question. First they have to find 100 people with malaria who are willing to try the new drug. If it cures the malaria infections of most of the people within one week, scientists will learn the answer to the question. Who does research? What is the purpose of research?

\section{Definition Explanation Technique}

The Definition Explanation Technique is effective for testing participants' comprehension of the definitions that you created for technical terms. To use this technique, provide participants with the definition of the term and then ask them to explain it to the group using local words or terms that express the concept.

Term: Screening

Question: Study staff will ask the person some questions to find out if the person has all the characteristics on the list. The person may also need to have some laboratory tests to find out about her health. For the research study you are participating in today, we asked you some questions to make sure you had all of the characteristics necessary. Could someone explain to the group what that process was like? What were the characteristics necessary to be in today's research?

Term: Multiple Concurrent Sex Partners

Question: During the past three months, Eliza has had more than one sexual partner. What does this mean to you?

Term: Informed Consent

Question: Before a woman decides if she wants to be in the study, study staff will review a document with her that explains the following:

- The purpose of the research, the study procedures, and the number of people in the study (i.e. study purpose).

- What she will have to do if she joins the research study and how long she will be in the study (i.e. study participation).

- Ways she may get hurt or have other problems as a result of being in the research study (i.e. risks).

- What she will get as a result of being in the research study (i.e. benefits).

- Being in the research study is her own decision; no one will force her to be in the study (i.e. voluntary participation).

- Study staff will not tell anyone that she is in the study or any of her personal information (i.e. confidentiality).

- Any money she may get for being in the study (i.e. compensation).

- Whom to contact if she has any questions or problems

- What she is due or allowed legally and morally for being in the study (i.e. rights as a participant). 
Do you remember going through this process to be in this study today? As the study staff are reviewing the document with her, the woman can ask any questions she has. At the end, she may take some time to decide if she wants to be in the study or not. She has been given information about the study, and now she may decide if she agrees to be in the study. What are some other ways to say that she has agreed to be in the study?

\section{Term Elicitation Technique}

The Term Elicitation Technique is effective for assessing participants' familiarity with a term or concept by generating a list of technical and nontechnical terms known to participants. To use this technique, present participants with explanations of a term and ask them to provide local words that express the concept. In some cases, you may find that using vignettes or stories may offer an effective way to add context to a term, such as different types of sexual behaviors.

Term: Family Planning Methods

Question: Sometimes a woman does not want to have a baby. There are different ways a woman can avoid becoming pregnant. What are some general terms for ways to avoid becoming pregnant?

Term: Casual Sex Partner

Question: Ngwash's friend Kabula has sex with a man named Malimy sometimes. Kabula and Malimy both have other sexual partners. What could you call a sexual partner a woman sees only sometimes?

\section{Term: Side Effects}

Question: Sometimes drugs can cause unwanted problems such as headaches, weight loss or weight gain, sleepiness, or problems with your liver. What else could you call these unwanted problems that result from a drug?

\section{Term Creation Technique}

The Term Creation Technique is effective for collecting participants' ideas about how to translate relatively new English scientific words that have no equivalents in the target language. It also indicates whether they prefer a new word 1) that sounds similar to the source language word or 2) whose meaning is clear upon hearing the word. To use this technique, describe the term or concept to participants, tell them the English word, and ask them to suggest words or terms in their local language. You may also choose to provide examples that have been developed by the translator or are local pronunciations.

\section{Term: Microbicides}

Question: Now I want to talk a little bit more about one prevention method scientists are testing. This method is for a woman to put a special gel in her vagina before having sex. The gel is a substance like a lubricant. The gel would prevent the virus from infecting a woman. Scientists call this method of HIV prevention "microbicide" in English. We are trying to create a good name for this method in our language. One option is to keep the word "microbicide" but give it our local pronunciation. What do you think about this word? What does it make you think of? 
A second option is to call it "substance that destroys microbes." What do you think about this word? What does it make you think of?

What other words would be a good name for this method?

\section{Determining the length and content of the focus group guides}

Determine how many question guides to create for Round One of the focus groups based on the number of terms in your preliminary lexicon and discreet content categories (i.e., research, reproductive health, sexual behavior, etc.).

We suggest a maximum of 10 to 12 questions per focus group and no more than two content categories per focus group. Discussions that contain more than the suggested number of questions/content areas can result in overly long complex discussions that can fatigue participants. Questions should be grouped by category and include moderator scripts which can be used to transition between questions and proves to clarify participant responses (see Example 4).

\section{Example 4 Focus Group Discussion Guide}

\section{Example Focus Group Guide: Assessing the Preliminary Lexicon}

Focus Group ID\#

Date Start Time

Moderator End Time

Note-taker \# Participants

\section{Introduction [Read to Participants]}

Our goal today is to discuss the different ways to talk about reproductive health in Swahili. Sometimes, researchers use words that are not words we typically use here in the community. When this happens, research participants and researchers may not always understand each other. Our discussion today will help researchers use Swahili more effectively in their research studies. It will also help future research participants to understand the research better.

Today we will be talking about various aspects of reproductive health. We want to know all the words and expressions that people use to describe these aspects of reproductive health. I hope that no one will feel embarrassed by the things I will be asking you! If you do feel embarrassed, you do not have to answer the question. Please remember that this is not an examination. We want to learn what words you use to talk about reproductive health. There are no right or wrong answers.

Okay let's get started by talking about different activities that take place when people go to a medical facility. 


\section{Example 4 Focus Group Discussion Guide (continued)}

\section{Question 1: (Term: Blood Test; Technique: Term Elicitation)}

Sometimes when people go to see a doctor they get their blood analyzed. The reason for analyzing the blood is to check it for the presence of a virus or bacteria that causes infection. Other times the reason is to check for other problems in the body.

What words could you use to refer to this process of checking the blood?

\section{Question 2: (Term: Pregnancy Test; Technique: Term Elicitation)}

Sometimes medical staff will ask the person to urinate in a cup. The medical staff will examine your urine to see if you are pregnant.

What words do you use to describe this process of medical staff examining your urine to see if you are pregnant?

\section{Question 3: (Term: Research; Technique: Term Explanation and Definition Explanation)}

Now let us talk about research studies.

Who knows what research is? Please tell us all that you know about research.

Research is the process of carefully studying information to discover one or more facts. Let me give you an example. Scientists have developed a new drug. They want to know if it will cure malaria infection within one week. They must do research to learn the answer to this question. First they have to find 100 people with malaria who are willing to try the new drug. If it cures the malaria infections of most of the people within one week, scientists will learn the answer to the question.

- Who does research?

- What is the purpose of research?

\section{Question 4: (Term: Clinical Trial; Technique: Term Explanation and Definition Explanation)}

Now let's talk about a particular kind of research.

Who knows what a clinical trial is? Please tell me all that you know about clinical trials.

A clinical trial is a kind of research study that 1) tests to see whether a new drug is safe, 2) tests a drug to see if it helps people who already have a medical problem, or 3) tests to see if the drug prevents people from getting the medical problem.

- Who can explain now what a clinical trial is?

- What is the purpose of a clinical trial? 


\section{Walking a Tightrope: Challenges of Using Illustrations in Bilingual LeXICONS}

Pictures and illustrations are often used in participant educational materials to facilitate understanding of clinical trial procedures in international settings. As part of this study, illustrations were developed to communicate a wide range of concepts, objects, and clinical procedures (e.g., anal sex, condom, pelvic exam). Use of illustrations to illicit terminology or translations proved problematic in this study for a number of reasons. Participants' interpretation of pictures was influenced by culturally specific norms and nuances, which were not always known during the development of the illustrations. In addition, if participants were unfamiliar with a particular clinical procedure, such as a pelvic exam, showing them an illustration was not helpful for generating discussion of appropriate terminology. As a result, techniques that involved pictures were not successful in this study. Therefore, the techniques recommended in this toolkit do not include illustrations; any development of pictures and illustrations should be approached with caution and informed by a rigorous research process.

\section{Step 3: Analyze Data from Development FGDs}

The goal of analysis is to synthesize the focus group so that you may further refine and revise your research lexicon. Each technique will yield different pieces of data that must be captured during the analysis process.

Analyze the transcript to identify the relevant portions of the discussions, per the objectives of the technique that was used. Following the completion of the focus groups, each discussion should be transcribed in its entirety and translated into English to facilitate analysis.

For questions that assessed a participants' familiarity with a term, such as Term Explanation and in some cases Term Elicitation, you will need to read though the transcript and determine whether participants understood the term. The first step may be to go back to the definition that was created in the preliminary lexicon and assess whether participants' explanations of the term are congruent.

The example below, for the term "safe sex," highlights how participants' discussion about a term can be compared with the definition of the term to assess comprehension. Analysis of these segments indicates that participants understand the concept of the term-they provide different Swahili words for "safe sex," such as "to have safe sex," and also mention that it means to "protect yourself." Moreover, they provide a number of examples (highlighted below) of what might be entailed in safe sex, including condom use, HIV testing, and mutual monogamy.

Term: Safe Sex

Definition: Sexual activity in which people protect themselves against diseases.

Term Explanation Question: What do you think is meant by the expression "safe sex"? Focus Group Discussion:

Respondent (R): Safe sex is like...to use condoms.

R: To have safe sex. 
R: Wife and husband shouldn't have sex outside their marriage.

$\mathrm{R}$ : As of now, the way I understand safe sex is having prevention during sexual intercourse.

R: To test first, and if you discover that you are well, you will have sex more safely; therefore, it is to protect yourself even [if] on another day you will fear to have sex outside your marriage. You will know that when I will go there I can acquire the disease, and when I return home she will know that it is me who has brought the disease.

For questions that assess participants' understanding of a term and definition, such as Definition Explanation, Term Elicitation, and in some cases Term Explanation, results will be determined through an analysis of the terms that were solicited. All solicited terms will need to be extracted from the translated transcript and sent to the study translator so that he/she may verify the English translation and provide notes on usage. The feedback from the translator will be used to determine whether the terms that were provided were indeed synonyms of the original lexical entry.

The example below, for the term "voluntary," highlights how terms that are elicited as part of the discussion can be utilized to assess participant understanding. Terms elicited from participants are highlighted. Several participants provided the exact terms we were referring to, while others mentioned similar concepts, such as a personal decision to participate in research. The translated transcript provided for this example; contains the translation of the terms that were originally used in the Swahili discussion that were verified by the study translator.

Term: Voluntary

Definition: When a person chooses freely whether to join research.

Term Elicitation Question: People are never forced to join research studies. They must always make the decision on their own, but are free to consult with whomever they would like. They choose freely to join research or not join research. What words would you use to describe when a person makes a decision freely to do something?

\section{Focus Group Discussion:}

$\mathrm{R}$ : She has done that voluntarily.

$\mathrm{R}$ : She is ready to do what... to participate.

$\mathrm{R}$ : Someone's decision.

$\mathrm{R}$ : To volunteer; someone else can say to volunteer.

Interviewer (I): To volunteer; what else, what is the other word? I mean this one has done, has decided to do something voluntarily, she has decided to do that thing. We say she has volunteered to do that thing; okay, what are the other words?

$\mathrm{R}$ : She has tossed herself into doing something.

$\mathrm{R}$ : To volunteer oneself.

For questions that utilize the Term Creation Technique, you will need to read through the transcript and identify all novel terms provided by participants, as well as participants' feedback on terms provided by the interviewer. All solicited terms should be extracted from the translated transcript and sent to the study translator, who will verify the English translation. An example of this process is provided in the case study in Appendix 2. 


\section{Step 4: Revise the Preliminary Research Lexicon}

Analysis of the focus groups is then used to revise the preliminary lexicon spreadsheet. Columns should be added to capture the questioning technique used, the terms elicited (if applicable), the definition for the terms elicited (if applicable), whether the technique was successful, and any notes on usage provided by participants or the translator.

\section{Adding elicited terms}

Terms elicited from the discussion of the terms "safe sex" and "voluntary" have been added to the spreadsheet to provide examples.

\section{Example 5 Revised Preliminary Lexicon Spreadsheet (Swahili)}

\begin{tabular}{|c|c|c|c|c|c|c|c|}
\hline \multirow{2}{*}{$\begin{array}{l}\text { Term } \\
\text { (English) }\end{array}$} & \multirow{2}{*}{$\begin{array}{l}\text { English } \\
\text { Definition }\end{array}$} & \multirow{2}{*}{$\begin{array}{l}\text { Translated } \\
\text { Definition } \\
\text { (Source } \\
\text { Language) }\end{array}$} & \multicolumn{5}{|c|}{ Round 1 Focus Groups } \\
\hline & & & $\begin{array}{l}\text { Question } \\
\text { Technique } \\
\text { Used }\end{array}$ & $\begin{array}{l}\text { Terms Elicited } \\
\text { (Target } \\
\text { Language) }\end{array}$ & $\begin{array}{l}\text { Definition } \\
\text { (English) }\end{array}$ & $\begin{array}{l}\text { Success } \\
(\mathbf{Y} / \mathbf{N})\end{array}$ & $\begin{array}{l}\text { Notes on } \\
\text { Usage }\end{array}$ \\
\hline \multirow[t]{3}{*}{ Safe Sex } & \multirow[t]{3}{*}{$\begin{array}{l}\text { Sexual } \\
\text { activity } \\
\text { in which } \\
\text { people } \\
\text { protect } \\
\text { themselves } \\
\text { against } \\
\text { diseases }\end{array}$} & \multirow[t]{3}{*}{$\begin{array}{l}\text { Anayefanya } \\
\text { mapenzi } \\
\text { kujilinda } \\
\text { dhidi ya } \\
\text { magonjwa ya } \\
\text { kuambukizwa } \\
\text { kama }\end{array}$} & \multirow[t]{3}{*}{$\begin{array}{l}\text { Term } \\
\text { Explanation }\end{array}$} & $\begin{array}{l}\text { Ngono } \\
\text { salama }\end{array}$ & $\begin{array}{l}\text { To have } \\
\text { safe sex }\end{array}$ & \multirow[t]{3}{*}{ Yes } & $\begin{array}{l}\text { Translator } \\
\text { suggested } \\
\text { ngono } \\
\text { salama is } \\
\text { commonly } \\
\text { used and } \\
\text { means safe } \\
\text { sex in regard } \\
\text { to HIV/AIDS }\end{array}$ \\
\hline & & & & $\begin{array}{l}\text { Kufanya } \\
\text { mapenzi } \\
\text { salama }\end{array}$ & Safe sex & & \\
\hline & & & & $\begin{array}{l}\text { Kuyjilinda } \\
\text { mwenyewe }\end{array}$ & $\begin{array}{l}\text { To protect } \\
\text { oneself }\end{array}$ & & \\
\hline \multirow[t]{4}{*}{ Voluntary } & \multirow{4}{*}{$\begin{array}{l}\text { When a } \\
\text { person } \\
\text { chooses } \\
\text { freely } \\
\text { whether } \\
\text { to join } \\
\text { research }\end{array}$} & \multirow{4}{*}{$\begin{array}{l}\text { Mtu } \\
\text { anapoamua } \\
\text { kwa hiari } \\
\text { yake kushiriki } \\
\text { kwenye utafiti }\end{array}$} & \multirow{4}{*}{$\begin{array}{l}\text { Term } \\
\text { Elicitation }\end{array}$} & Kujitolea & Volunteer & \multirow[t]{2}{*}{ Yes } & \\
\hline & & & & Hiari & Voluntarily & & $\begin{array}{l}\text { A common } \\
\text { phrase } \\
\text { used in } \\
\text { nonresearch } \\
\text { settings }\end{array}$ \\
\hline & & & & $\begin{array}{l}\text { Uamuzi wa } \\
\text { mtu }\end{array}$ & $\begin{array}{l}\text { Someone's } \\
\text { decision }\end{array}$ & & \\
\hline & & & & Kujitoa & $\begin{array}{l}\text { To } \\
\text { volunteer } \\
\text { oneself }\end{array}$ & & \\
\hline
\end{tabular}




\section{Revising the term definitions}

In both of the cases highlighted in Example 5, the techniques were successful and were used to verify that participants understood the terms and also allowed researchers to elicit terms that could also be used to describe the original concept. In some cases, however, participant discussion will be used to revise the definitions that were created as part of the preliminary lexicon.

If participants are unable to understand the term definition or explanation, it may be possible to utilize the focus group discussion to identify key words, concepts, or terms that can be revised. For example, for the term "Randomization," research staff hoped to elicit nontechnical terms that could be used to explain this concept. A definition was developed in the preliminary lexicon: "a system to assign participants into different research groups. In this system, participants are put into groups completely by chance."

To assess the participants' understanding of the definition, we used the Definition Explanation Technique where we provided participants with the definition and asked them to explain the concept or provide synonymous terms.

When researchers conduct a clinical trial, they use a system to assign participants into different research groups. In this system, participants are put into groups completely by chance. The researcher does not decide which participants go into each group. The participants also do not choose their group. This system helps to ensure fairness. Can I get a volunteer to explain this system to the group?

A portion of the discussion from the focus groups is provided below. Participants' discussion indicated that they understood this was a research concept and that it included participants being divided into two groups, but there was not a clear understanding of the "random" assignment of participants.
R: To take chances.
R: She has consented.
R: She has taken a chance.
R: She has taken a chance, this one has voluntary consented.
R: She has been appointed.

In this case, the definition was revised to include a nontechnical example that clarified the concept of random assignment, as follows:

Sometimes in research, people are put into different groups. One way to put people into different groups is to use a system that assigns each person to a group by chance. For example, each person could be assigned to either Group A or Group B. There is no person who chooses the group; a computer chooses the group each person will join. One person may go into Group $B$, a second person may go into Group $B$, and a third person may go into Group A. 


\section{Step 5: Develop FGD Guides to Assess the Revised Lexicon}

Now you will conduct a second set of focus groups to finalize the research lexicon. The objective for this set of focus groups is (1) to verify the revised lexicon definitions, (2) to verify terms that were elicited in the first round of focus groups, and (3) to identify the preferred term(s) based on participant feedback.

\section{Identifying the correct questioning technique}

Once again, ensuring that the correct questioning technique is chosen will be a critical step in the process. The four questioning techniques used in Round 1 along with an additional technique, Verbal Multiple Choice can be used in the second round of focus groups.

\section{Table 2 Questioning Techniques to Assess Revised Lexicon}

\begin{tabular}{|c|c|c|}
\hline Technique & Description & Data Collected \\
\hline $\begin{array}{l}\text { Term } \\
\text { Explanation }\end{array}$ & $\begin{array}{l}\text { Tests whether participants are familiar with } \\
\text { technical and nontechnical terms that have been } \\
\text { translated by providing the translated terms and } \\
\text { asking participants to explain them to the group. }\end{array}$ & $\begin{array}{l}\text { - Insight on participant familiarity } \\
\text { with technical and nontechnical } \\
\text { terms. } \\
\text { - List of technical and nontechnical } \\
\text { terms. }\end{array}$ \\
\hline $\begin{array}{l}\text { Definition } \\
\text { Explanation }\end{array}$ & $\begin{array}{l}\text { Tests a definition that has been developed by } \\
\text { providing participants with a term and its definition } \\
\text { and then asking them to explain the term (in their } \\
\text { own words) to the group, or answer questions that } \\
\text { assess their understanding of the concept. }\end{array}$ & $\begin{array}{l}\text { - Feedback on translated definition } \\
\text { (i.e., words or concepts that are } \\
\text { difficult to understand). } \\
\text { - List of technical and nontechnical } \\
\text { terms. }\end{array}$ \\
\hline $\begin{array}{l}\text { Term } \\
\text { Elicitation }\end{array}$ & $\begin{array}{l}\text { Identifies whether participants are familiar with an } \\
\text { existing term or concept by providing them with } \\
\text { the translatable definition that you developed and } \\
\text { asking them to provide matching terms. In some } \\
\text { cases, you may also use scenarios to identify terms } \\
\text { that are appropriate in a specific context (i.e., } \\
\text { doctor's office, among peers). }\end{array}$ & $\begin{array}{l}\text { - List of technical and nontechnical } \\
\text { terms. } \\
\text { - Feedback on explanation of term } \\
\text { (i.e., words or concepts that are } \\
\text { difficult to understand). }\end{array}$ \\
\hline $\begin{array}{l}\text { Term } \\
\text { Creation }\end{array}$ & $\begin{array}{l}\text { Gathers participants' ideas about how to translate } \\
\text { relatively new English scientific words that have } \\
\text { no equivalents in the target language by providing } \\
\text { them with a detailed explanation of the idea, object, } \\
\text { or process. Asks participants to reiterate their } \\
\text { understanding of the concept and then provide } \\
\text { terms or phrases in the target language that could be } \\
\text { used to describe the concept. }\end{array}$ & $\begin{array}{l}\text { - New terms created by participants. } \\
\text { - Feedback on terms that were pro- } \\
\text { vided to participants. }\end{array}$ \\
\hline $\begin{array}{l}\text { Verbal } \\
\text { Multiple } \\
\text { Choice }\end{array}$ & $\begin{array}{l}\text { Verifying the term(s) elicited in the first round of } \\
\text { focus groups, as well as identifying participant term } \\
\text { preferences. }\end{array}$ & $\begin{array}{l}\text { - Term preferences. } \\
\text { Participant feedback that may } \\
\text { include: understanding of terms, } \\
\text { reason for term preference, usage } \\
\text { notes for each term. }\end{array}$ \\
\hline
\end{tabular}




\section{Verbal Multiple-Choice Technique}

The Verbal Multiple-Choice Technique, which should only be used in the second round of focus groups, is effective for both verifying the term elicited in the first round of focus groups, as well as identifying participant term preferences.

To use this technique, we will ask participants to do one of the following:

1. Match the term definition with their preferred choice(s) of words that include: (a) words elicited in the first round of focus groups, and (b) terms in the preliminary lexicon.

2. Match the term definition with their preferred choice(s) of explanation that include: (a) explanations provided by participants in the first round of focus groups, and (b) explanations developed by the translator.

3. Match the elicited term with the explanation choice(s) that they prefer. The choices will include: (a) explanation of the term elicited in the first round of focus groups and (b) explanation of the term that was developed by the translator.

\section{Term: Safe Sex}

Technique: Verbal Multiple-Choice, matching definition to a preferred term.

Question: It is important for people who have sexual intercourse to take actions to protect themselves against sexually transmitted infections such as HIV. These protective actions may include using condoms and having only one sexual partner. Which of the following expressions best describes these actions?

a. Mapenzi salama [safe sex].

b. Ngono isiyo salama [unsafe sex].

c. Kujilinda mwenyewe [protecting oneself].

For those of you who chose [most voted answer], why do you like that answer?

For those of you who chose [next most voted answer], why do you like that answer?

For those of you who chose [next most voted answer], why do you like that answer?

\section{Term: Blood Draw}

Technique: Verbal Multiple-Choice, matching definition to a preferred explanation.

Question: Sometimes blood is removed from a vein in the arm in order to test the blood. Which of the following explanations makes the most sense to describe this process?

a. Anachukua damu. [She is drawing the blood.]

b. Kuna sindano inatoa damu kwenye mkono. [There is an injection which is taking blood from the arm.] 
Term: Clinical Trial

Technique: Verbal Multiple-Choice, matching an elicited term to an explanation.

Question: There is a type of research study sometimes called a jaribio la kitabibu [clinical trial] that: (1) tests to see whether a new drug is safe, (2) tests a drug to see if it helps people who already have a medical problem, or (3) tests to see if a drug prevents people from getting the medical problem. [Repeat 1-3 as necessary.] Which of the following four choices is not the purpose of a clinical trial?

a. Tests to see if a new drug is safe.

b. Tests a drug to see if it helps people who already have a medical problem.

c. Tests a drug to see if people will pay for the drug.

d. Tests a drug to see if it prevents people from getting a medical problem.

Technique selection should be guided by the results of the first round of focus groups.

In cases where a questioning technique was NOT successful a second round focus will allow you to test an existing or revised term definition using the Term Elicitation, Term Explanation or Definition Explanation Techniques (see What to Do With Unsuccessful Techniques on page 19). It is important to note that a second focus group will not allow you to finalize the lexicon for these terms, as the data will need to be verified during a separate focus group.

In cases where a questioning technique was successful a second round of focus groups will allow you to verify the terms that were elicited in the first round or assess whether participants prefer one term over another.

- To verify terms that were elicited in the first round you may ask participants to either provide technical or nontechnical terms using the Term Explanation Technique, or ask them for an explanation of the elicited term using the Definition Explanation Technique. Using either of these techniques in the second round of focus groups will allow you to gauge whether the terms are useful for communicating the original concept.

- To assess participants' term preferences you can use a new technique, Verbal Multiple Choice, which will allow you to identify whether participants favor one term over another while capturing information about the nuances of each term and the context in which it should be used.

\section{Determining the length and content of the focus group guides}

Once again you can determine how many focus group guides to create for round two based on the number of terms/questions and discreet content categories. While questions in this round may seem shorter because they are multiple-choice, the participant discussion about choice preferences is likely to be lengthy. Thus, we suggest a maximum of 10 to 12 questions per focus group.

Unlike the first round of focus groups, many of the questions in the second round will have predetermined answer choices. For questions that utilize the Verbal Multiple-Choice Technique, a data collection form, which can be filled out by moderators during the focus group discussion, offers a quick and useful way to get a preliminary snapshot of the data (see Example 6). 


\section{What to Do with Unsuccessful TechniQues?}

In some cases, focus group discussions may indicate that a technique was not successful. There may be cases where researchers are trying to elicit terms by providing a simplified explanation of a term developed by the translator or in previous clinical research that researchers expect participants will understand.

However, in some cases, discussion may indicate that participants are not familiar with the underlying term or concept. In these cases, it may be necessary to use additional focus groups to assess participant understanding of related terms or concepts prior to a revision of the Preliminary Lexicon definition.

For example, in the case of the term "Pap Smear," researchers hoped to elicit technical and nontechnical terms using the Term Elicitation Technique. To this end, the following question was developed:

"A doctor may examine a woman's vagina as part of a health exam. The doctor will insert this metal instrument called a speculum into the vagina. The speculum opens the vagina and helps the doctor see the inside of the vagina. The doctor can also see the opening of the organ where a baby grows. The doctor uses a stick with a cotton tip to collect a sample of tissue from inside the vagina. What do you call this kind of examination by a doctor?"

Researchers also utilized a set of pictures, which had been used in previous clinical trials, to facilitate participant understanding of the process that was being described. The discussion, however, indicated that participants were not familiar with this type of procedure. A portion of the discussion is provided below:

R: Maybe she [doctor] widens the woman's vagina so that she may see what is inside. Mmm, I mean if she wants to clean her.

$\mathrm{R}$ : We don't know.

I: Isn't there even one of you who have ever gone to the doctor to have an investigation such as this one?

R: Mmm, I have happened to go there to be operated on... I also lay on the bed just like how that woman is lying.

I: Okay, when you were being operated on. Apart from this one who was operated on, isn't there anyone else who has had an investigation such as this?

R: No [murmuring].

Given that participants were not familiar with the process, it was not feasible to identify technical or nontechnical terms that could be used to describe this process. Due to the scope of the question and probes, it was also not possible to ascertain whether there were aspects of the process that were familiar to participants.

In this case, the Definition Explanation Technique was used in a second round of focus groups. This technique allowed researchers to assess participants' understanding of a revised simplified definition for Pap smear. This additional data can provide information on the specific aspects of the term that were hard to comprehend and yield information regarding the best words and colloquial terms that can be used as part of the definition for Pap smear. 


\section{Example 6 Verbal Multiple-Choice Data Collection Form (Swahili)}

\section{DATA COLLECTION FORM-VERIFICATION GUIDE FORM MODERATOR INSTRUCTIONS}

This form will record information captured in the focus group discussion. For questions with multiple-choice answers, as indicated below, please write the number of respondents who selected each answer in the right column.

\section{QUESTION \\ ANSWER CHOICES \\ NUMBER OF

PART I: REPRODUCTIVE HEALTH \& RESEARCH

1. Risks a. Hasara [disadvantage/loss]

b. Hatarishi [risks-translator's choice]

c. Madhara [adverse effects]

2. Benefits

a. Faida [benefits-translator's choice]

b. Manufaa [benefits-translator's choice]

c. Msaada [help, aid]

3. Male Sexual

a. Mume [husband]

Partner

b. Mpenzi [lover]

c. Mchumba [fiancé]

d. Mshikaji [buddy/close friend]

e. Hawara [boyfriend or sex partner not married to]

f. Rafiki [friend]

g. Wake [husband]

h. Mpenzi wa kiume [male lover]

i. Buzi [lover you can gain materials from, not love] 


\section{Step 6: Analyze Data from Verification FGDs}

For questions that were used to (1) assess whether participants understand revised definitions and (2) elicit technical and nontechnical terms using revised definitions, the analysis process that was used in the first round should be followed (see Section 2, Step 2).

Following the completion of the focus groups, each discussion should be transcribed in its entirety and, if possible, translated into English to facilitate analysis. Review each transcript to identify the relevant portions of the discussions, per the objectives of the technique that was utilized.

\section{Verifying terms and assessing term acceptability}

For all verbal multiple-choice questions, the participant voting (i.e., on term preferences) will be captured on the data collection form. This initial tally will allow you to identify terms that were preferred by the focus group participants and verify whether the elicited terms from the first set of focus groups were acceptable for each concept.

Acceptability criteria will need to be determined by the research team, although it is suggested that "successful" terms be within ten percentage points of the overall vote winner. Even though all terms that have participant votes may be acceptable to some degree, establishing cutoff criteria ensures that your final lexicon has terms that have been verified by a larger portion of study participants from the target population for the trial.

On the data collection form, shown below, two distinct scenarios are highlighted for the terms "side effects" and "family planning." For "side effects," the term "problems" was not chosen by participants in any of the focus group discussions. Although this term may have been suggested by participants or the translator, the data collection indicated that this term was not favored by participants and should not be included in the research lexicon entry for "side effects."

The verbal multiple-choice question for the term "family planning" elicited three terms in the first round of focus groups as answer choices. In this case, each term was selected by about the same number of participants. While the term "birth planning ways" is the overall "winner," the other terms may also be acceptable and should not be excluded. Qualitative analysis should be conducted to provide insight into participants' preferences, especially given the uneven distribution of votes across the focus groups.

Example 7 Data Collected from Verbal Multiple Choice Technique During FGDs

\begin{tabular}{|l|l|c|c|c|c|}
\hline Question & Term Choices & $\begin{array}{c}\text { Total } \\
\text { N }(\%)\end{array}$ & $\begin{array}{c}\text { FGD } 002 \\
(\mathbf{n}=11)\end{array}$ & $\begin{array}{c}\text { FGD } 004 \\
(\mathbf{n}=10)\end{array}$ & $\begin{array}{c}\text { FGD } 005 \\
(\mathbf{n}=10)\end{array}$ \\
\hline \multirow{2}{*}{ Side Effects } & a. Problems & $00(0)$ & 00 & 00 & 00 \\
\cline { 2 - 6 } & b. Side effects & $31(100)$ & 11 & 10 & 10 \\
\hline \multirow{2}{*}{$\begin{array}{l}\text { Family Planning } \\
\text { Method }\end{array}$} & c. Family planning method & $09(29)$ & 00 & 03 & 06 \\
\cline { 2 - 6 } & d. Birth planning ways & $11(35)$ & 10 & 00 & 01 \\
\cline { 2 - 6 } & e. Family planning & $09(29)$ & 00 & 06 & 03 \\
\hline
\end{tabular}




\section{Analysis of verification phase transcripts}

You will need to read though the transcript and identify relevant participant feedback that may provide insight into the reasons for participant preferences. This may include: explanation of term(s), comparison of term(s), reasons for preferential choice of a term, and notes on specific term usage.

In the example below, the participants are asked to indicate their preference for a term that signifies "side effects." The question and a portion of the transcript are provided below; portions of the text that were isolated as part of the analysis are highlighted. Participants' conversation provides insight into the unanimous preference for the term "side effects." In this case, participant discussion highlights the alternative connotation of the term "problems," which could be used to describe general life challenges or nonmedical catastrophes.

\section{Approaching The Analysis: Software Considerations}

The analysis as we present it does not necessitate any special software for qualitative analysis; rather, the person analyzing the transcripts simply records the relevant information onto the spreadsheet. However, researchers may find it useful to use qualitative data analysis software to code information that would then be entered onto the spreadsheet. Segments of the transcript could then be easily reviewed if necessary. For example, you could code the transcript segment for a given term as "technique successful" or "technique unsuccessful." You could then easily review the coded segments of terms for which the questions were "unsuccessful" when developing focus group questions for the second round.

Term: Side Effects

Question: Sometimes unwanted things happen when you take a drug, such as a headache, a rash, or weight gain. Which of the following word choices best describes these unwanted things?

a. Matatizo [problems]

b. Madhara [side effects]

\section{Focus group 002}

I: For those of you who chose Matatizo [problems], why do you like that answer?

[All participants chose the term madhara.]

I: Why we have to use a word madhara [side effects] and not I get some problems?

R: I think we cannot use problems because mostly they know if you have a problem like someone pass away (laughing) so I think we can use that side effects.

$\mathrm{R}$ : Shelhe got a problem someone pass away or... shelhe has misfortune or has a sick person.

R: I was thinking we can use a word "side effect."

R: I see if we use a word "problem" most people they see problems is likely misfortune or as you say your house was burn or even accident.

R: Mmm! I have the same idea.

$\mathrm{R}: E e$.

R: Eeeh! 
In the example below, the participants are asked to indicate their preference for a term that signifies "family planning." The question and portions of the transcripts are provided below; portions of the text that were isolated as part of the analysis are highlighted. The conversation from participants across the three focus groups provides insight into the differences in term preferences across the groups.

Participants in FGD 002 prefer "birth planning ways," which they feel better captures that wide range of family planning options as well as the utility of family planning when it comes to child spacing. On the other hand, participants in the other focus groups prefer the terms "family planning" and "family planning methods," sometimes used interchangeably, which they cite as being commonly understood by community members.

Term: Family Planning

Question: There are many methods to prevent a woman from becoming pregnant. These include birth control pills, injectables, condoms, and Norplant. Which of the following words would a nurse use to describe these methods?

a. Njia za uzazi wa mpango [family planning method]

b. Anapanga uzazi [birth planning ways]

c. Kupanga uzazi [family planning]

\section{Focus group 002}

I: For those of you who chose njia za uzazi wa mpango [family planning method], why do you like that answer?

[No respondents chose this term.]

\section{R: Family planning its mean that family planning are inside the stomach.}

I: For those of you who chose njia za anapanga uzazi [birth planning ways], why do you like that answer?

R: This one explain on how you can plan when you can get a first born, second, and last one; that's how it differentiates.

\section{Focus group 004}

I: Mmm! If we say kupanga uzazi [family planning], how did you see that?

R: Family planning is more understood with many people than birth planning ways.

$\mathrm{R}:$ It is short-you can explain to any person.

R: I am adding that because this word is in the community; they understand family planning.

\section{Focus group 005}

I: And those who said let's use njia za uzazi wa mpango [family planning method]?

R: If we go together with our society, members of our society surround us. Many people got used to family planning. I see if we use... if we use the saying family planning [method], it is known to many people. 
R: I am still in the same position. That word is very correct; even a village person if you tell her family planning [method] it is being correct. If you tell her, maybe let's go to the family planning methods, you are being correct. You explain to her maybe now it's injection or pills or it's condom.

R: Now if you tell her family planning methods so you are giving birth in plan, you are planning.

\section{What to do with an unsuccessful tech- nique in the verification phase}

The lexicon development process allows for as many rounds of focus groups and revisions of the preliminary lexicon as necessary (see Figure 2). Although most terms will not need more than two rounds of data collection, additional data collection is acceptable if you find that you need to refine a question or use a different technique.

\section{Step 7: Finalize the Research Lexicon}

Analysis of the verification focus groups should provide the data on term acceptability needed to finalize the research lexicon. Columns should be added for each term, including: the number (and percentage) of votes the term received across all focus groups, notes on reasons for participant preference, and whether the term should be included in the final lexicon per the predetermined eligibility criteria.
Figure 2 Research Lexicon Process

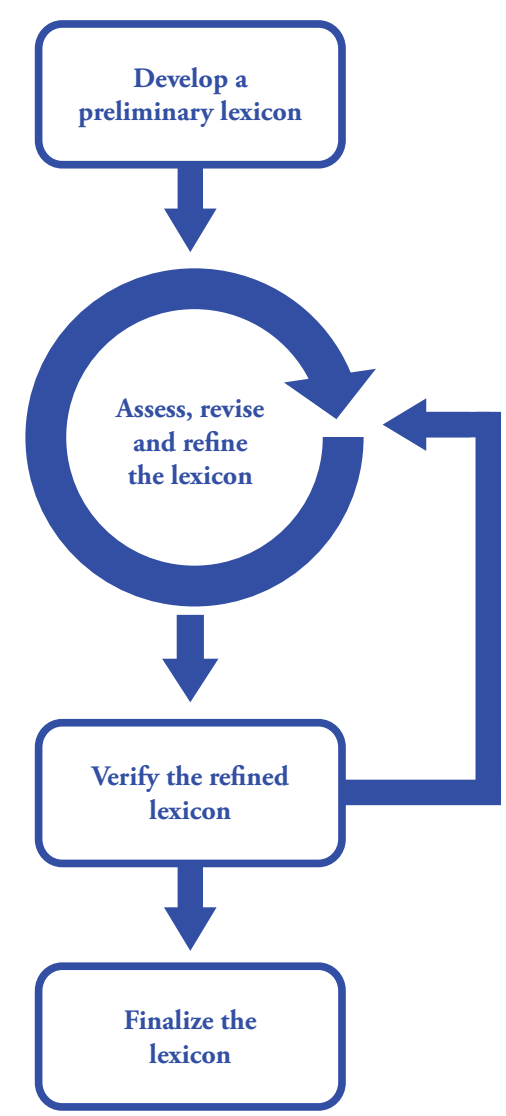




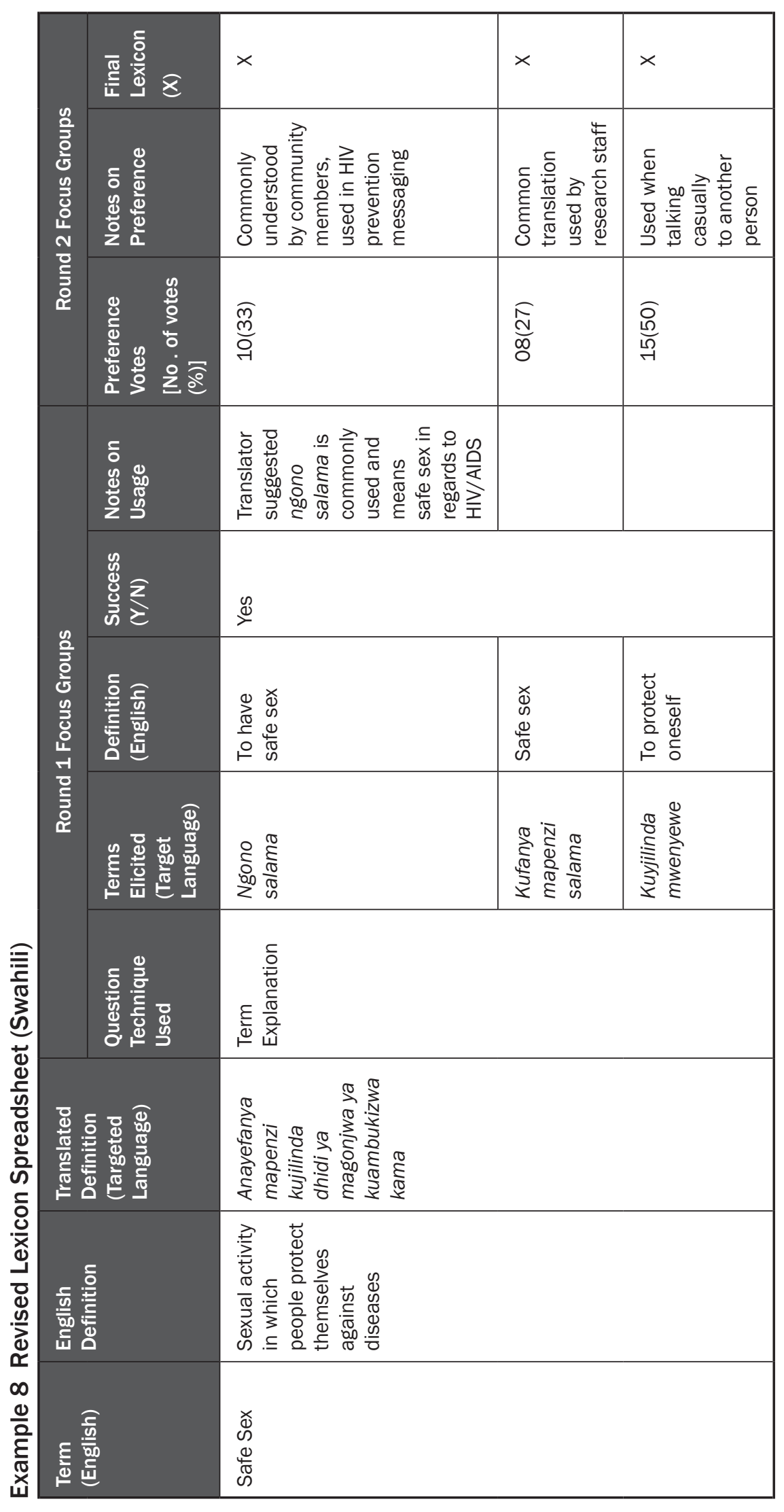




\section{Develop a final research lexicon entry}

Using the revised lexicon spreadsheet, you are now ready to compile a final bilingual lexicon. The final research lexicon should contain:

- The English Term

- The Term Definition: This should be the definition that was used and understood by participants in the verification phase.

- Source Language Verified Terms: Acceptable terms, per participant preferences in the verification round, should be included in English and in the source language. Source language translations should be the same as were used in the focus groups.

- English Translation of Verified Terms: Technical translations of each verified term should also be included, in both English and the source language.

- Notes on Usage for each term (if applicable).

\section{Example 9 Final Lexicon Entry (Swahili)}

\begin{tabular}{|c|c|c|c|c|c|}
\hline $\begin{array}{l}\text { English } \\
\text { Term }\end{array}$ & $\begin{array}{l}\text { English } \\
\text { Definition }\end{array}$ & $\begin{array}{l}\text { Target Language } \\
\text { Translation of } \\
\text { Definition }\end{array}$ & $\begin{array}{l}\text { Target } \\
\text { Language } \\
\text { Term }\end{array}$ & $\begin{array}{l}\text { English } \\
\text { Translation of } \\
\text { Target Language } \\
\text { Term }\end{array}$ & $\begin{array}{l}\text { Notes on } \\
\text { Usage }\end{array}$ \\
\hline \multirow[t]{3}{*}{ Safe Sex } & \multirow[t]{3}{*}{$\begin{array}{l}\text { Sexual activity } \\
\text { in which } \\
\text { people protect } \\
\text { themselves } \\
\text { against diseases }\end{array}$} & \multirow[t]{3}{*}{$\begin{array}{l}\text { Anayefanya mapenzi } \\
\text { kujilinda dhidi } \\
\text { ya magonjwa ya } \\
\text { kuambukizwa kama }\end{array}$} & $\begin{array}{l}\text { Ngono } \\
\text { salama }\end{array}$ & To have safe sex & $\begin{array}{l}\text { Commonly } \\
\text { understood } \\
\text { expression, } \\
\text { specifically } \\
\text { pertaining to HIV } \\
\text { prevention }\end{array}$ \\
\hline & & & $\begin{array}{l}\text { Kufanya } \\
\text { mapenzi } \\
\text { salama }\end{array}$ & Safe sex & $\begin{array}{l}\text { Typical } \\
\text { translation used } \\
\text { by research staff }\end{array}$ \\
\hline & & & $\begin{array}{l}\text { Kuyjilinda } \\
\text { mwenyewe }\end{array}$ & $\begin{array}{l}\text { To protect } \\
\text { oneself }\end{array}$ & \\
\hline
\end{tabular}




\section{Deciding Which Term to Use in a Clinical Trial ConteXt}

Although numerous terms may have been elicited and may be acceptable to participants, an important part of the verification process is to review the terms elicited and determine which would be appropriate and easily understood by participants in a clinical trial context.

\section{Case 1: The formal research term(s) is/are equally, or more, acceptable than the informal term(s).}

A review of terms for a concept may yield a number of formal and colloquial terms that are equally acceptable to participants. Some of these terms may be used by participants in casual discussions among peers, but those same terms would be considered inappropriate for use in discussions with trial research team members (e.g., doctors, nurses, counselors, community outreach workers). In cases where multiple terms are acceptable to the study population, it is critical to assess the "notes on usage" from the development phase to decide which term may be more appropriate in a clinical trial context.

\section{Case 2: The informal term(s) is/are more acceptable that the formal term.}

In other cases, a review of acceptable terms for a concept may indicate that an informal term is widely acceptable to study participants, while a formal research term for that same concept is not. In cases where the formal/research term is not acceptable to participants, it is also critical to review the "notes on usage" to decide whether the informal term could be appropriate for use in a clinical trial to maximize participant comprehension. For example, for the term "safe sex," the most widely preferred terms in Swahili were "kuyjilinda mwenyewe" and "ngono salama"; whereas both of these terms were not the standard research translation, they were commonly used by the community and would be considered acceptable in a clinical trial context.

Another option for cases in which an informal or colloquial term is more widely understood may be to use the formal term in participant communication but include the colloquial term in study staff scripts and documents, so that it may be used by staff if participants do not understand the formal translation.

It is critical that review of the data collected for each term and the final decision to use a term in clinical trial processes and participant communication should involve not only the site investigator but also the translator and other team members who may have experience with the target study population and may be able to provide additional information on the appropriate usage context for each term. 


\section{LEXICON DATABASE}

In tandem with the development of this toolkit, the Population Council built a searchable database, Translations in Context: A Lexicon of Field-tested HIV Clinical Trial Terminology, for researchers conducting clinical trials of microbicides (and other HIV prevention technologies) as a resource for field-tested translations in multiple languages. Instead of creating new translations every time a new trial is conducted at a specific site, researchers have access to the existing lexicons that have been used in clinical trial communities. The database is user-friendly, available with any internet browser, and supports multiple languages and alphabets. Currently, the database contains clinical trial terminology in English, Xhosa, Zulu, Setswana, and Swahili (see Appendix 3 for an example of the Swahili lexicon). The lexicon database is available at: http://lexicon.popcouncil.org (see Appendix 4 for sample screens from the database). 


\section{APPENDIX 1. PRE-RESEARCH ACTIVITIES}

We recommend that the following resources be available prior to beginning the lexicon process.

\section{Staff}

You will need a multidisciplinary research team that includes social scientists and clinical trial investigators, as well as translators and data collectors who are familiar with the local population to be recruited for the clinical trial.

\section{Figure 3 Research Staff Organization Chart}

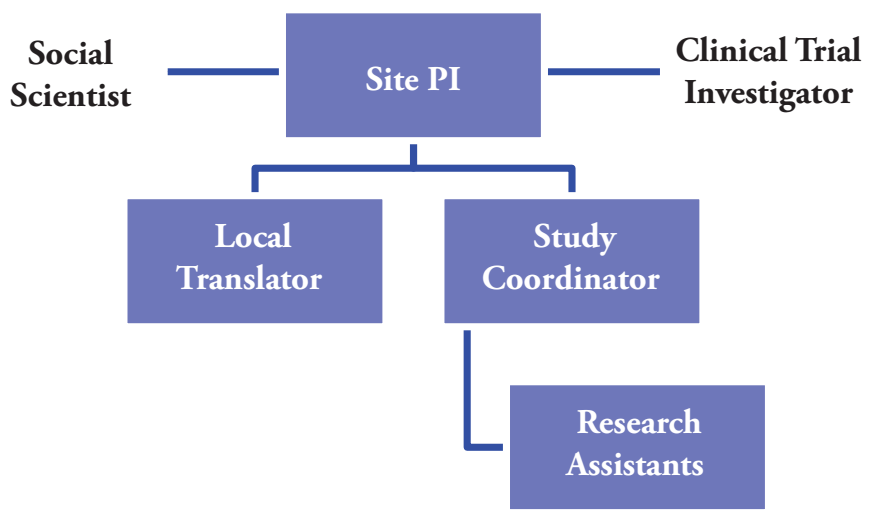

- Principal Investigator (PI). This person should be trained in social science and familiar with the study population.

- Social Scientist. This person will serve as a co-investigator and should be trained in ethnolinguistic methods.

- Clinical Trial Investigator. This person will serve as a co-investigator and will provide feedback on the accuracy of the definitions developed by the social scientist.

- Study Coordinator. This person will coordinate all data collection and analysis activities. S/he will also need to manage day-to-day administrative activities, including research team meetings and budget management.

- Local Translator. This person should be qualified to translate from the source language (e.g., English) into the target language (e.g., Swahili). Ideally, this person's mother tongue should be the target language; the source language may be a language learned later in life. In addition, the translator should be a member of the larger community where the trial will be taking place, if not of the study population.

- Research Assistants (RAs) (2). RAs should be trained in how to effectively lead focus group discussions. For research pertaining to reproductive health, the moderators should be of the same gender as the study population, given that sensitive topics related to sexual behaviors may be discussed. Data collected will need to be quickly transcribed; this activity may be carried out by the RAs, hence these individuals also need to have experience with computers and word processing. 


\section{Budget}

The budget for the development of a research lexicon will differ depending on the scope of activities and the local setting. However, it is critical to provide adequate budget support for all research activities to ensure success in developing a local research lexicon.

\section{Staff salaries}

Reimbursement for staff time is critical to ensure dedicated effort to research activities. Salaries should be commensurate with experience and local equivalencies.

- The Local PI (50\% FTE) will oversee community engagement activities, provide training for the focus group moderators, and oversee all data collection and activities. S/he will also participate in the analysis of the data and provide administrative oversight.

- The Study Coordinator (50\% FTE) will provide day-to-day management for all administrative and research activities.

- Two RAs (100\% FTE) will participate in community engagement activities, recruit focus group participants, moderate the discussions, lead transcriptions/translation and assist with analysis activities.

- A Social Scientist (20\%) will provide leadership in the development of the data collection instruments and analysis of the data collected throughout the lexicon development process.

- A Clinical Trial Investigator (5\%) will provide significant input to the development of the preliminary plain-language definitions and will review the data collection instruments and final lexicon entries.

\section{Recruitment activities}

Recruitment of participants with similar characteristics to clinical research subjects often requires time and travel. Additionally, in many cases community engagement activities within the local community are advised in order to: (1) obtain necessary approvals, (2) garner community support for the study, and (3) aid in identification of recreational/entertainment facilities appropriate for participant recruitment. Community engagement activities may last several days.

\section{Data collection and analysis}

Focus groups with approximately 10 to 15 terms require approximately 4 to 5 hours for setup, moderation, and wrap-up; additional time should be budgeted for travel. Focus group discussions will need to be recorded, transcribed, and translated; thus, site staff should have access to at least two digital recorders and a computer. Transcription and translation are time-consuming activities and require significant review and revisions by team members.

Research staff should estimate at least 3 to 5 hours of transcription and 4 to 6 hours for translation per hour of audio recording. In addition, several hours should be budgeted for a second translator and the Study PI to review initial transcriptions and translations to ensure accuracy and quality. 


\section{Participant reimbursements}

Participants should be reimbursed for time and travel costs associated with participating in research activities. The reimbursement amount should be commensurate with locally identified rates.

\section{Data analysis}

Sufficient time is needed to analyze data from the development phase of focus groups in order to inform the results of the verification phase of data collection. For each term included in the first round of focus groups, we estimate at least three hours of analysis which will include: identifying elicited terms, and the social scientist working with the translator and study PI to fill out the lexicon spreadsheet and develop questions for the verification round of focus groups.

We estimate approximately three hours per term for the analysis of the verification focus groups and development of the final lexicon. This will include analysis, compilation of the data collection forms, qualitative analysis of the transcripts, and working with the Site PI and translator to develop final lexicon entries. 


\section{APPENDIX 2. CASE STUDIES}

\section{Case Study 1: Male Sex Partner}

HIV prevention clinical trials often include eligibility criteria, behavioral data collection, and treatment regimens that require communicating with a participant about sexual behavior. One of the challenges of discussing sexual behavior in a clinical trial setting can be the cultural nuances of terminology around partner types. In some cases, the technical translation for "male sex partner" may not be used widely or may be limited to a specific relationship setting (i.e., married partner, casual partner) or may limit the participant from disclosing additional sexual partners.

\section{Step 1: Development of preliminary lexicon}

In order to develop a "translatable definition" for this term, we began by developing a preliminary lexicon:

\begin{tabular}{|l|l|l|}
\hline Term (Swahili) & Definition (English) & Source of Definition \\
\hline Male Sex Partner & $\begin{array}{l}\text { A man who inserts his penis into a } \\
\text { woman's vagina }\end{array}$ & Pl and Social Scientist \\
\hline
\end{tabular}

\section{Step 2: Develop data collection instruments to assess the preliminary lexicon}

Our objective for the term "male sex partner" was to learn local words, expressions, and classifications for different types of male sexual partners. We used the Elicitation Technique to develop a set of questions that would allow us to capture terms used by potential study participants. Questions using the Elicitation Technique present participants with definitions of terms and semantic categories and ask them to provide local words that express these definitions.

We used the following question: "When a man inserts his penis into woman's vagina, who is he to that woman? What can you call him?"

\section{Step 3: Analyze FGDs}

Participants provided a number of different words and expressions throughout the focus group discussion, which was transcribed and translated. A portion of the text is provided below with elicited terms highlighted, as they would be during the analysis process.

$\mathrm{R}$ : According to the present situation to say the truth, in the past it was between wife and husband but nowadays even if you will meet in the street "I love you, you love me," okay already... For me I will call him a boyfriend, $\mathrm{mmm}$.

R: Or a lover.

$\mathrm{R}:$ A two minutes' lover?

$\mathrm{R}$ : Very often the word that is used is a lover. 
R: Yes, or even if he will be with me for two months he will be my fiancé.

I: Two months. Do you mean if they will be together for all that period? Therefore, even if they didn't do anything, still he will be a fiancé meaning that....

R: Yes, a fiancé, because they are together.

$\mathrm{R}$ : There is a big male goat - someone you can gain materials and not love from being with him (others laughing).

$\mathrm{R}$ : Many words my sweet, there is my lotion they are calling many words... (laughing).

\section{Step 4: Revise the preliminary research lexicon}

The translator reviewed the words elicited for both terms and also provided additional notes on usage. All terms were then entered into the lexicon spreadsheet, as follows:

\section{Revised Lexicon Spreadsheet: Male Sex Partner (Swahili)}

\begin{tabular}{|c|c|c|c|c|c|c|}
\hline \multirow{2}{*}{$\begin{array}{l}\text { Term } \\
\text { (English) }\end{array}$} & \multirow{2}{*}{$\begin{array}{l}\text { English } \\
\text { Definition }\end{array}$} & \multicolumn{5}{|c|}{ Round 1 Focus Groups } \\
\hline & & $\begin{array}{l}\text { Question } \\
\text { Technique } \\
\text { Used }\end{array}$ & $\begin{array}{l}\text { Terms } \\
\text { Elicited (Target } \\
\text { Language) }\end{array}$ & $\begin{array}{l}\text { Definition } \\
\text { (English) }\end{array}$ & $\begin{array}{l}\text { Success } \\
(\mathrm{Y} / \mathrm{N})\end{array}$ & Notes on Usage \\
\hline \multirow{5}{*}{$\begin{array}{l}\text { Male Sex } \\
\text { Partner }\end{array}$} & \multirow{5}{*}{$\begin{array}{l}\text { A man who } \\
\text { inserts his } \\
\text { penis into } \\
\text { a woman's } \\
\text { vagina }\end{array}$} & \multirow{5}{*}{$\begin{array}{l}\text { Term } \\
\text { Elicitation }\end{array}$} & Mume & Husband & \multirow[t]{5}{*}{ Yes } & \\
\hline & & & Mchumba & Fiancé & & $\begin{array}{l}\text { Translator said } \\
\text { that traditionally } \\
\text { fiancé implies } \\
\text { no sex before } \\
\text { marriage. }\end{array}$ \\
\hline & & & Mpenzi & Lover & & \\
\hline & & & Hawara & Boyfriend & & $\begin{array}{l}\text { Not gender } \\
\text { specific, means } \\
\text { unmarried sex } \\
\text { partner. Commonly } \\
\text { used by adult } \\
\text { persons, and } \\
\text { rarely used among } \\
\text { youth. }\end{array}$ \\
\hline & & & Buzi & $\begin{array}{l}\text { Big male } \\
\text { goat (lover) }\end{array}$ & & $\begin{array}{l}\text { Someone you } \\
\text { can gain/get } \\
\text { "things" from. Is } \\
\text { considered a rude } \\
\text { way to identify } \\
\text { someone. }\end{array}$ \\
\hline
\end{tabular}




\section{Step 5: Develop data collection instruments to assess the revised lexicon}

A number of terms were identified using the Term Elicitation Technique during the first round of focus group discussions. During the second round, we were interested in learning the word(s) women might use and understand when in a medical context.

We retained the definition of male sex partner to be, "a man who inserts his penis inside a woman's vagina" but added, "that is, a man with whom she has sexual intercourse." The reason for our addition is that there is an established term for sexual intercourse in Swahili, and we thought it might help to clarify the question for participants.

We developed a focus group question using the Verbal Multiple-Choice Technique that used the following scenario:

"A counselor asks a woman, Limi, if she has a man in her life who inserts his penis inside her vagina, that is, a man with whom she has sexual intercourse. Do any of the following words refer to a man who inserts his penis inside Limi's vagina? You can raise your hand for more than one answer."

We did not indicate whether the woman and her male partner were married. We then offered eight selections from which women should choose their preferences. Two choices came from the translator, five came from the focus groups, and the last choice was the dictionary translation of the English word "friend."

\begin{tabular}{|l|l|l|}
\hline Term (Target Language) & Definition (English) & Source of Term \\
\hline Mshikaji & Friend & Dictionary \\
\hline Rafiki & Friend/casual lover & Translator \\
\hline Wake & Husband & Translator \\
\hline Mume & Husband & FGD Round 1 \\
\hline Mchumba & Fiancé & FGD Round 1 \\
\hline Mpenzi Wa Kiume & Male lover & FGD Round 1 \\
\hline Hawara & Boyfriend or girlfriend & FGD Round 1 \\
\hline Buzi & Big male goat (lover) & FGD Round 1 \\
\hline
\end{tabular}

A data collection form was developed to capture the tally of participant preferences during the focus group. This provided a way of initially assessing participants' preferences and the acceptability of the terms. 
Data Collection Form: Male Sex Partner (Swahili)

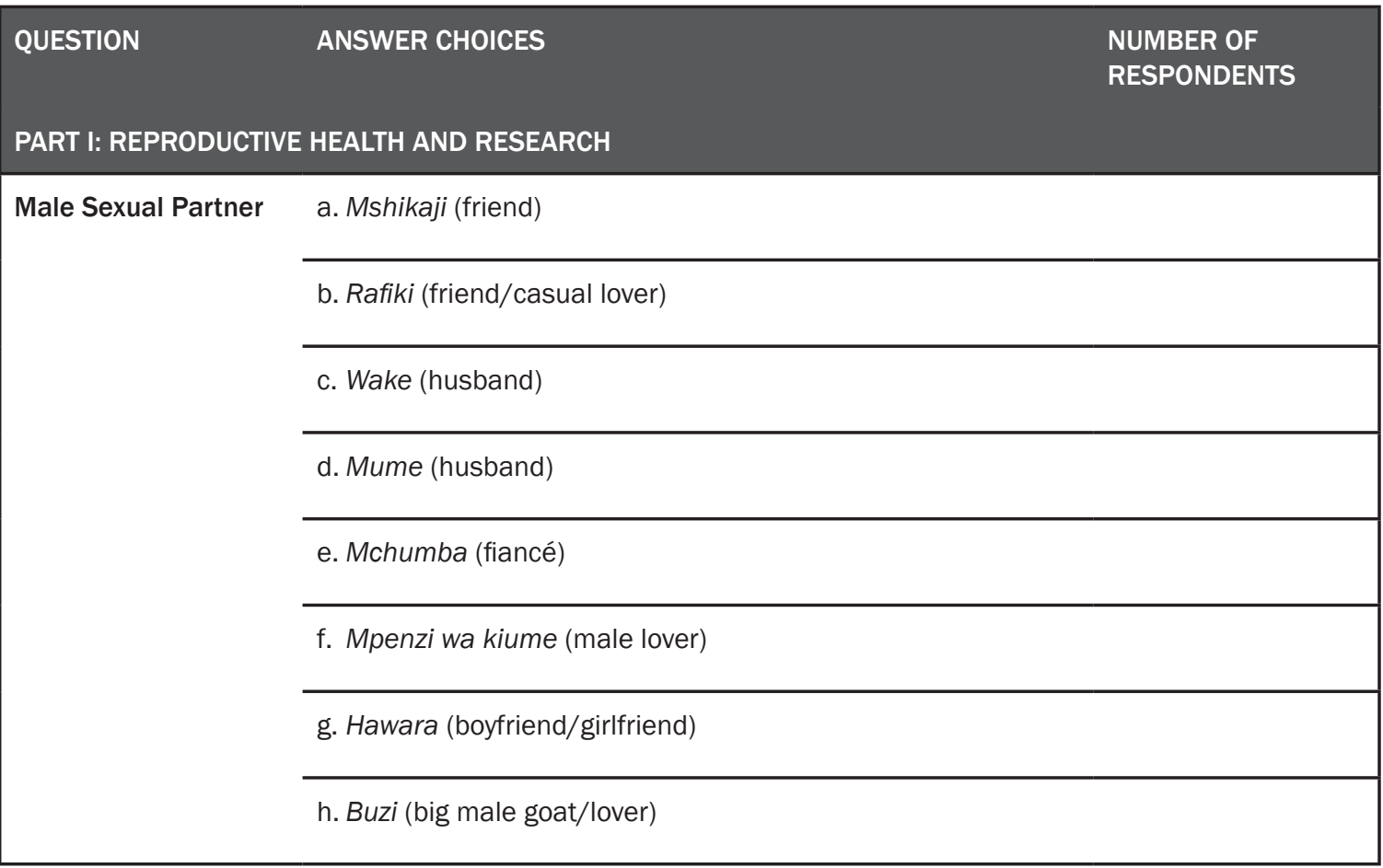

\section{Step 6: Analyze focus group discussions}

\section{Verifying terms and assessing term acceptability}

More than half of the participants across both focus groups (16 out of 30) indicated that hawara was the most appropriate term for the scenario we described. Nine of the participants also liked mpenzi wa kiume, and two participants liked mchumba or buzi.

\begin{tabular}{|c|c|c|c|c|c|}
\hline $\begin{array}{l}\text { Term } \\
\text { (English) }\end{array}$ & Term Choices (Swahili) & $\begin{array}{l}\text { Total } \\
\mathrm{N}(\%)\end{array}$ & $\begin{array}{l}\text { FGD } 001 \\
\qquad N=15\end{array}$ & $\begin{array}{l}\text { FGD } 002 \\
N=15\end{array}$ & Usage Notes \\
\hline \multirow{8}{*}{$\begin{array}{l}\text { Male } \\
\text { Sexual } \\
\text { Partner }\end{array}$} & a. Mshikaji (friend) & $01(3)$ & 00 & 01 & \\
\hline & b. Rafiki (friend/casual lover) & $00(0)$ & 00 & 00 & $\begin{array}{l}\text { Not chosen by any } \\
\text { participants. }\end{array}$ \\
\hline & c. Wake (husband) & $01(3)$ & 01 & 00 & \\
\hline & d. Mume (husband) & $00(0)$ & 00 & 00 & \\
\hline & e. Mchumba (fiancé) & $02(7)$ & 01 & 01 & \\
\hline & f. Mpenzi wa kiume (male lover) & 09(30) & 05 & 04 & \\
\hline & g. Hawara (boyfriend/girlfriend) & $16(53)$ & 08 & 08 & $\begin{array}{l}\text { Participants liked this } \\
\text { term because it did not } \\
\text { imply marriage or stable } \\
\text { partnership. }\end{array}$ \\
\hline & h. Buzi (big male goat/lover) & $02(7)$ & 00 & 02 & \\
\hline
\end{tabular}




\section{Qualitative analysis of verification phase transcripts}

Participants were asked to indicate their preference for a term that signified "male sexual partner." The question and a portion of the transcripts are provided below; portions of the text that were isolated as part of the analysis are highlighted. Participants' discussion provides insight into preferential selection of the terms that mean "male lover" and "boyfriend." Participants indicated that the terms "husband" and "fiancé" would not indicate a sex partner outside of those specific relationships. Additionally, participants indicated that the term for "friend/casual lover" was not always indicative of a sexual relationship.

I: For those who chose husband [wake], why we should use that word?

R: If we call husband we are wrong because he is not yet her husband, he has to be lover because you are just doing lovers things you can separate on the way.

R: If you are not married to him, you will call him a boyfriend [hawara].

I: For those who chose hawara (boyfriend/girlfriend), why should we use that word?

$\mathrm{R}$ : This is a boyfriend because it's a person, a man different from your husband. They spend just a short time, then they separate, everyone is going on their own way. So that's why we are calling a boyfriend, because she is not recognized to the man's relatives.

I: For those of you who chose mchumba (fiancé), why do you like that answer?

$\mathrm{R}$ : We used the word fiancé because he wanted to penetrate.

R: It's her fiancé if he is expecting to marry her.

R: No. It's her male lover.

I: For those who did not choose rafiki (friend), why should we not use that term?

$\mathrm{R}$ : We cannot call friend because he penetrated her.

$\mathrm{R}$ : Aaah, we must call that way lover [mpenzi], because it is familiar.

R: Lover [mpenzi] is a person who is recognized as a (sexual partner).

\section{Step 7: Finalize the research lexicon}

Analysis of the verification focus groups provided data on term acceptability and preferences that were added to the lexicon spreadsheet for this term. 


\begin{tabular}{|c|c|c|c|c|c|c|}
\hline \multirow{3}{*}{ 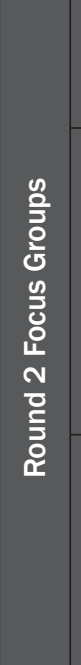 } & 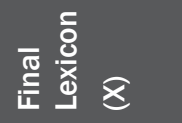 & & & & $\times$ & \\
\hline & 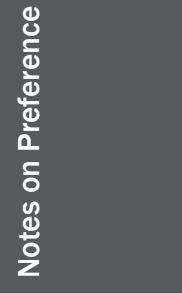 & & & & 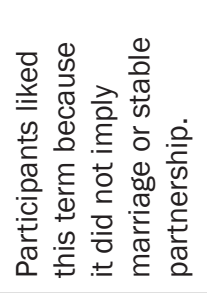 & \\
\hline & 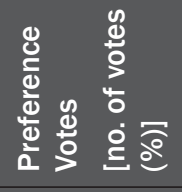 & $\frac{\widehat{m}}{\frac{m}{0}}$ & $\underset{\widetilde{\sigma}}{\widetilde{\sigma}}$ & $\begin{array}{l}\text { oิ } \\
\text { ๓े } \\
\text { ᄋ }\end{array}$ & $\begin{array}{l}\widehat{\widehat{D}} \\
\stackrel{0}{0} \\
\underline{G}\end{array}$ & $\widehat{E}$ \\
\hline \multirow{5}{*}{ 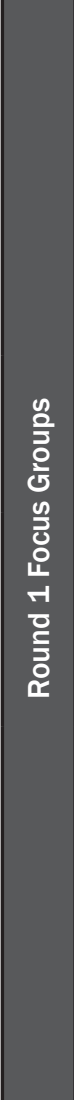 } & 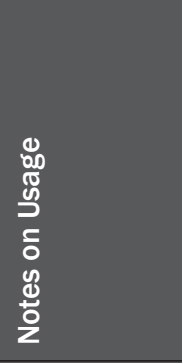 & & 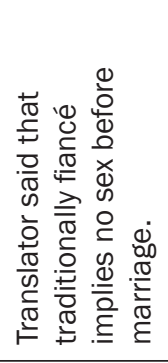 & & 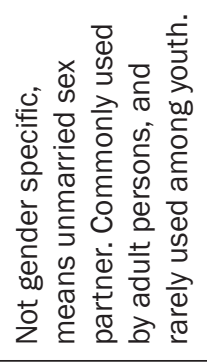 & 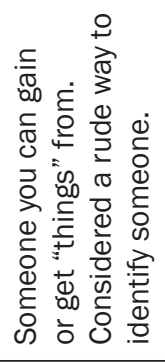 \\
\hline & 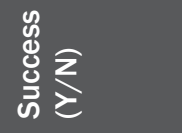 & \multicolumn{5}{|l|}{$\stackrel{\mathscr{N}}{\nu}$} \\
\hline & 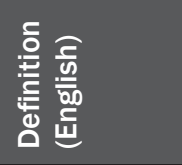 & $\begin{array}{l}\frac{0}{2} \\
\frac{0}{\pi} \\
\frac{0}{01} \\
\frac{0}{1}\end{array}$ & 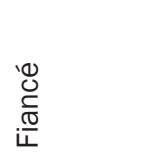 & ఏे & 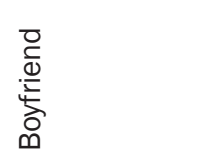 & 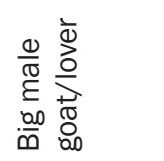 \\
\hline & 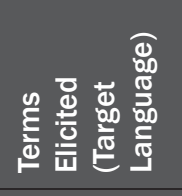 & 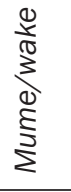 & 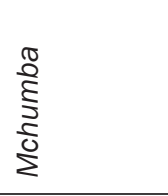 & $\begin{array}{l}\bar{N} \\
\bar{\Phi} \\
\stackrel{2}{\Sigma}\end{array}$ & $\begin{array}{l}\frac{\pi}{\pi} \\
\frac{\pi}{\pi} \\
\frac{1}{10}\end{array}$ & $\begin{array}{l}\bar{N} \\
\text { D }\end{array}$ \\
\hline & 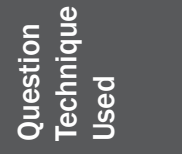 & \multicolumn{5}{|c|}{ 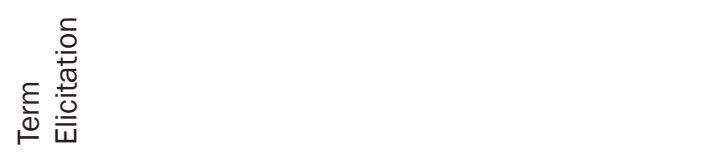 } \\
\hline 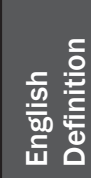 & & \multicolumn{5}{|c|}{ 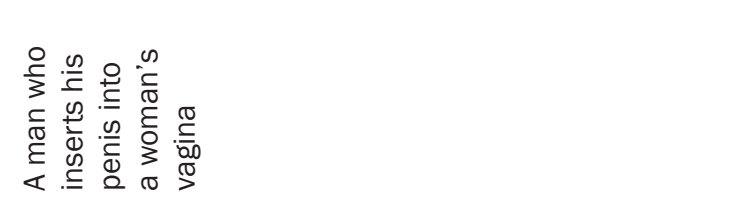 } \\
\hline 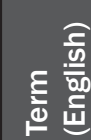 & & \multicolumn{5}{|c|}{ 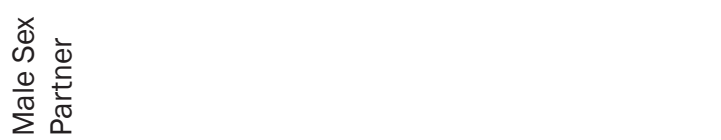 } \\
\hline
\end{tabular}




\section{Develop final lexicon entries}

Based on the selection guidelines that were established for term preference and the data collected on acceptability, we developed a final bilingual lexicon entry for this term.

\begin{tabular}{|l|l|l|l|l|l|}
\hline English Term & $\begin{array}{l}\text { English } \\
\text { Definition }\end{array}$ & $\begin{array}{l}\text { Target Language } \\
\text { translation of } \\
\text { Definition }\end{array}$ & $\begin{array}{l}\text { Target } \\
\text { Language } \\
\text { Term }\end{array}$ & $\begin{array}{l}\text { English } \\
\text { Translation of } \\
\text { Target } \\
\text { Language Term }\end{array}$ & Notes on Usage \\
\hline $\begin{array}{l}\text { Male Sexual } \\
\text { Partner }\end{array}$ & $\begin{array}{l}\text { A man who } \\
\text { inserts his penis } \\
\text { inside a woman's } \\
\text { vagina; that is, a } \\
\text { man with whom } \\
\text { she has sexual } \\
\text { intercourse }\end{array}$ & $\begin{array}{l}\text { Mwanaume } \\
\text { anayeingiza uume } \\
\text { wake ndani ya uke } \\
\text { wa mwanamke }\end{array}$ & Hawara & $\begin{array}{l}\text { Boyfriend, } \\
\text { girlfriend }\end{array}$ & $\begin{array}{l}\text { Not gender } \\
\text { specific, but this } \\
\text { would mean } \\
\text { unmarried } \\
\text { sex partner. } \\
\text { Commonly used } \\
\text { by adult persons, } \\
\text { and rarely used } \\
\text { among youths' } \\
\text { relationships. }\end{array}$ \\
\hline
\end{tabular}

\section{Case Study 2: Pre-Exposure Prophylaxis (PrEP)}

Another challenge that has arisen in HIV prevention trials is the lack of scientific and technical vocabulary, specifically when novel technologies are developed. One recent example has been the use of different drugs prophylactically to prevent HIV infection. This technology has been labeled PrEP. The successful implementation of a prevention strategy that includes PrEP will rest on a clear understanding of the concept by the target population.

\section{Step 1: Development of preliminary lexicon}

In order to develop a "translatable definition" for this term, we began by developing a preliminary lexicon:

\begin{tabular}{|l|l|l|}
\hline Term (Swahili) & Definition (English) & Source of Definition \\
\hline PrEP & $\begin{array}{l}\text { An HIV prevention method used } \\
\text { before a person has sex }\end{array}$ & Previous clinical trials \\
\hline
\end{tabular}

\section{Step 2: Develop data collection instruments to assess the preliminary lexicon}

Our objective for the term "PrEP" was to learn participants' ideas about how to translate this relatively new term that has no equivalent in the target language. We used the Term Creation Technique.

Questions using the Term Creation Technique describe the thing or concept to participants, provide the method's English names, ask for their reactions to words the translator and study staff have developed, and ask participants to suggest names for the methods in their local language. 
We used the following question:

"Sometimes researchers are trying to look for new techniques of preventing infections of $H I V$, okay? There are new techniques which the researchers are doing to try to see if they can prevent infections of HIV. These techniques are called Pre-Exposure Prophylaxis. This is a more professional name and means a way of protecting someone before they get HIV infection. What does it mean? A way to prevent oneself, to protect someone before she gets infections of HIV. What could we call this?"

\section{Step 3: Analyze focus group discussions}

Participants provided feedback on the terms that were provided (i.e., PrEP) and also suggested a number of novel names during the focus group discussion, which was transcribed and translated. An excerpt of the text is provided below with elicited terms highlighted, as they would be during the analysis process.

\section{R: Prepo.}

$\mathrm{R}:$ It is protection... therefore should we call it "protection"?

I: Therefore what do you say? How many agree with the word protection, how many do we agree with the word protection?

$\mathrm{R}:$ Maybe let me give my opinion, because if you will go to tell someone the word protection simply s/he will not understand what is that protection for? ... I mean if you will not explain to her/him.

R: I mean if you didn't explain to her she can't understand what Prepo is.

I: Therefore, what word do you think we should use, or what should we do?

R: If we say the word Prep, it will be difficult for people to understand; now in order for that person... you can't tell someone, another doesn't understand, but if you will use the word protection from infection, she will know that protection is a Swahili word. This means that you will start explaining to her that it is protection for what.

$\mathrm{R}:$ Maybe a protection against HIV infections.

$\mathrm{R}$ : To prevent oneself against infections of $H I V$.

\section{Step 4: Revise the preliminary research lexicon}

The translator reviewed the words elicited for this term and also provided additional notes on usage. All terms were then entered into the lexicon spreadsheet, as follows: 
Revised Lexicon Spreadsheet: PrEP (Swahili)

\begin{tabular}{|c|c|c|c|c|c|c|}
\hline \multirow{2}{*}{$\begin{array}{l}\text { Term } \\
\text { (English) }\end{array}$} & \multirow{2}{*}{$\begin{array}{l}\text { English } \\
\text { Definition }\end{array}$} & \multicolumn{5}{|c|}{ Round 1 Focus Groups } \\
\hline & & $\begin{array}{l}\text { Question } \\
\text { Technique } \\
\text { Used }\end{array}$ & $\begin{array}{l}\text { Terms } \\
\text { Elicited (Target } \\
\text { Language) }\end{array}$ & $\begin{array}{l}\text { Definition } \\
\text { (English) }\end{array}$ & $\begin{array}{l}\text { Success } \\
(\mathrm{Y} / \mathrm{N})\end{array}$ & Notes on Usage \\
\hline \multirow[t]{4}{*}{ PrEP } & \multirow[t]{4}{*}{$\begin{array}{l}\text { An HIV } \\
\text { prevention } \\
\text { method used } \\
\text { before a person } \\
\text { has sex }\end{array}$} & $\begin{array}{l}\text { Term } \\
\text { Creation }\end{array}$ & $\begin{array}{l}\text { Kujikinga kabla } \\
\text { ya maambukizi }\end{array}$ & $\begin{array}{l}\text { Protecting } \\
\text { myself } \\
\text { before } \\
\text { infections }\end{array}$ & \multirow[t]{4}{*}{ Yes } & \\
\hline & & & $\begin{array}{l}\text { Kinga ya } \\
\text { maambukizi ya } \\
\text { ukimwi }\end{array}$ & $\begin{array}{l}\text { Protection } \\
\text { against } \\
\text { infection of } \\
\text { HIV }\end{array}$ & & \\
\hline & & & Prepo & Prep & & \\
\hline & & & Purep & $\mathrm{N} / \mathrm{A}$ & & \\
\hline
\end{tabular}

\section{Step 5: Develop data collection instruments to assess the revised lexicon}

A number of terms were identified using the Term Creation Technique during the first round of focus group discussions. During the second round, we were interested in learning the word(s) that women preferred to use for this concept.

We used the Verbal Multiple-Choice Technique to better understand women's preference for a term for PrEP. We developed the following question to assess women's terminology choices:

"There is a new method for HIV prevention that scientists are testing in clinical trials. In this new method, a person will take a pill to prevent becoming infected with HIV. In English, this method is called PrEP. People have suggested several names for this method in Swahili. Which one do you like best?"

\begin{tabular}{|l|l|l|}
\hline Term (Target Language) & Definition (English) & Source of Term \\
\hline Yaani najikinga kabla ya maambukizi & Protecting myself before infections & FGD Round 1 \\
\hline Purep & N/A & FGD Round 1 \\
\hline Prepo & N/A & FGD Round 1 \\
\hline Kinga ya maambukizi ya ukimwi & Protectionagainst infections of HIV & FGD Round 1 \\
\hline
\end{tabular}

A data collection form was developed to capture the tally of participant preferences during the focus group. This provided a way of initially assessing participants' preferences and the acceptability of the terms. 
Data Collection Form: PrEP (Swahili)

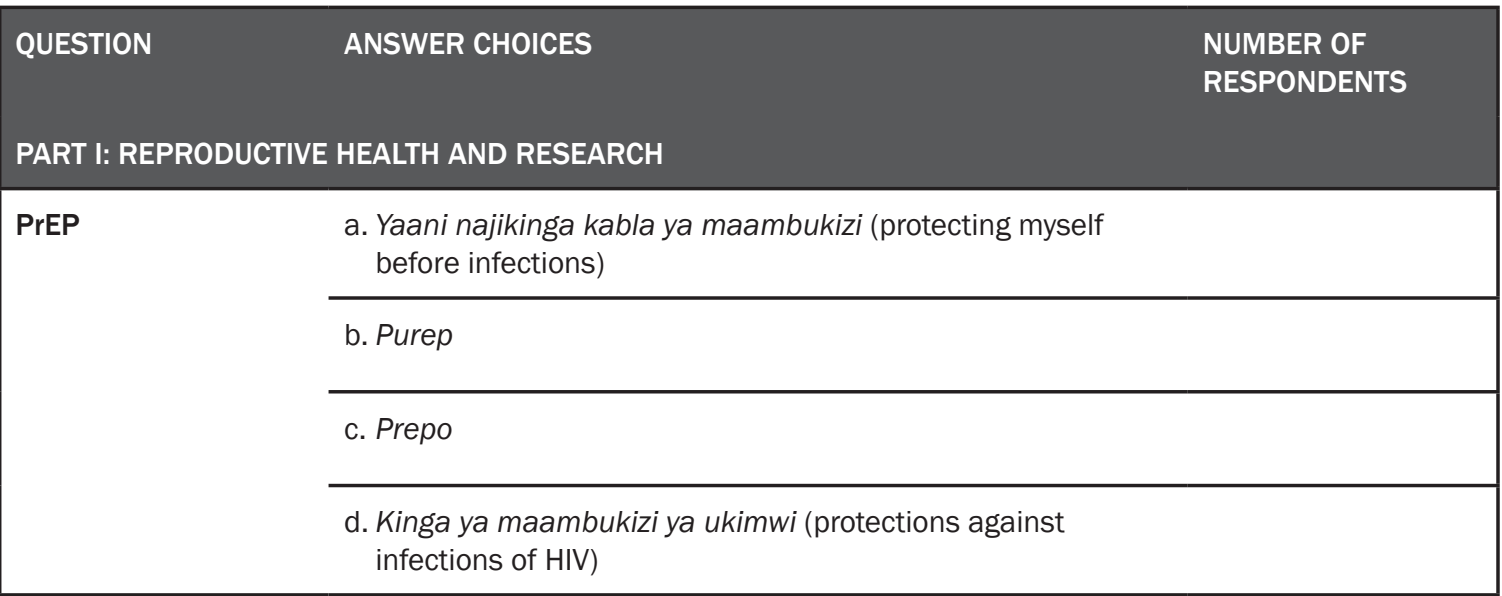

\section{Step 6: Analyze focus group discussions}

\section{Verifying terms and assessing term acceptability}

More than half of the participants across both focus groups (15 out of 30) indicated that the term kinga ya maambukizi ya ukimwi was the most appropriate description of the term "pre-exposure prophylaxis." Seven of the participants also like yaani najikinga kabla ya maambukizi, and four participants liked purep.

\begin{tabular}{|c|c|c|c|c|c|}
\hline Term (English) & Term Choices & $\begin{array}{l}\text { Total } \\
\mathrm{N}(\%)\end{array}$ & $\begin{array}{l}\text { FGD } 001 \\
\qquad N=15\end{array}$ & $\begin{array}{l}\text { FGD } 002 \\
\qquad N=15\end{array}$ & Usage Notes \\
\hline \multirow[t]{4}{*}{ PrEP } & $\begin{array}{l}\text { a. Yaani najikinga kabla ya } \\
\text { maambukizi (protecting } \\
\text { myself before infections) }\end{array}$ & $07(23)$ & 04 & 03 & \\
\hline & b. Purep & 04(14) & 02 & 02 & Sounded too clinical. \\
\hline & c. Prepo & $00(0)$ & 00 & 00 & \\
\hline & $\begin{array}{l}\text { d. Kinga ya maambukizi } \\
\text { ya ukimwi (protections } \\
\text { against infections of HIV) }\end{array}$ & $15(50)$ & 07 & 08 & $\begin{array}{l}\text { Most descriptive, } \\
\text { easy to understand. }\end{array}$ \\
\hline
\end{tabular}

\section{Qualitative analysis of verification phase transcripts}

Participants were asked to indicate their preference for a term that could be used to mean PrEP. The question and an excerpt of the transcripts are provided below; portions of the text that were isolated as part of the analysis are highlighted. Participants' discussion highlights the preference for phrases that define PrEP versus novel words or Swahili pronunciations. Additionally, participants preferred the phrase that specifically cited HIV prevention, noting that it was more precise and less likely to be confused with general infectious-disease prevention or a condom that protects against other infections. 
I: For those of you who chose kinga ya maambukizi ya ukimwi [protection against infections of HIV], why do you like that answer?

$\mathrm{R}:$ I think the correct answer is protection against infections of HIV, because you cannot say I protect myself before infection.

R: Even me I see we could use a word protection against infection of HIV because if you say prepo... because others they didn't go to school they would not understand the meaning of prepo.

R: You know a word prepo (laughing) first even to pronounce is difficult, then you might forget it but protection against infections of HIV it's understood but it needs more explanation.

R: Aaaah! You explain to her, I need the drugs because of....

R: Eeeh! But that purep, even here in the village they will ask what is that.

R: It's difficult. Better prevention against HIV is something widely open... it cannot bring confusion that mean condom.

\section{Step 7: Finalize the Research Lexicon}

Analysis of the verification focus groups provided data on term acceptability and preferences that were added to the lexicon spreadsheet for the term (see opposite page).

\section{Develop final lexicon entries}

Based on the selection guidelines that were established for term preference and the data collected on acceptability, we developed a final bilingual lexicon entry for the term.

Given the guideline we set for classification of term success, only the term kinga ya maambukizi ya ukimwi was successful as a translation of the English term "Pre-Exposure Prophylaxis." Our bilingual lexicon entry appeared as follows:

\begin{tabular}{|l|l|l|l|l|l|}
\hline English Term & $\begin{array}{l}\text { English } \\
\text { Definition }\end{array}$ & $\begin{array}{l}\text { Target Language } \\
\text { Translation of } \\
\text { Definition }\end{array}$ & $\begin{array}{l}\text { Target } \\
\text { Language } \\
\text { Term }\end{array}$ & $\begin{array}{l}\text { English } \\
\text { Translation of } \\
\text { Target Language } \\
\text { Term }\end{array}$ & Notes on Usage \\
\hline PrEP & $\begin{array}{l}\text { An HIV prevention } \\
\text { method used } \\
\text { before a person } \\
\text { has sex }\end{array}$ & $\begin{array}{l}\text { Njia ya kujikinga } \\
\text { na VVU kabla mtu } \\
\text { hajafanya ngono }\end{array}$ & $\begin{array}{l}\text { Kinga ya } \\
\text { maambukizi } \\
\text { ya ukimwi }\end{array}$ & $\begin{array}{l}\text { Protecting myself } \\
\text { before infections }\end{array}$ & $\begin{array}{l}\text { Casual phrasing } \\
\text { that would } \\
\text { be easy to } \\
\text { understand, is } \\
\text { not specific to the } \\
\text { clinical setting. }\end{array}$ \\
\hline
\end{tabular}

Another challenge that has arisen in HIV prevention trials is the lack of scientific and technical vocabulary, specifically when novel technologies are developed. One recent example has been the use of different drugs prophylactically to prevent HIV infection. This technology has been labeled PreExposure Prophylaxis (PrEP). The successful implementation of a prevention strategy that includes PrEP will rest on a clear understanding of the concept by the target population. 


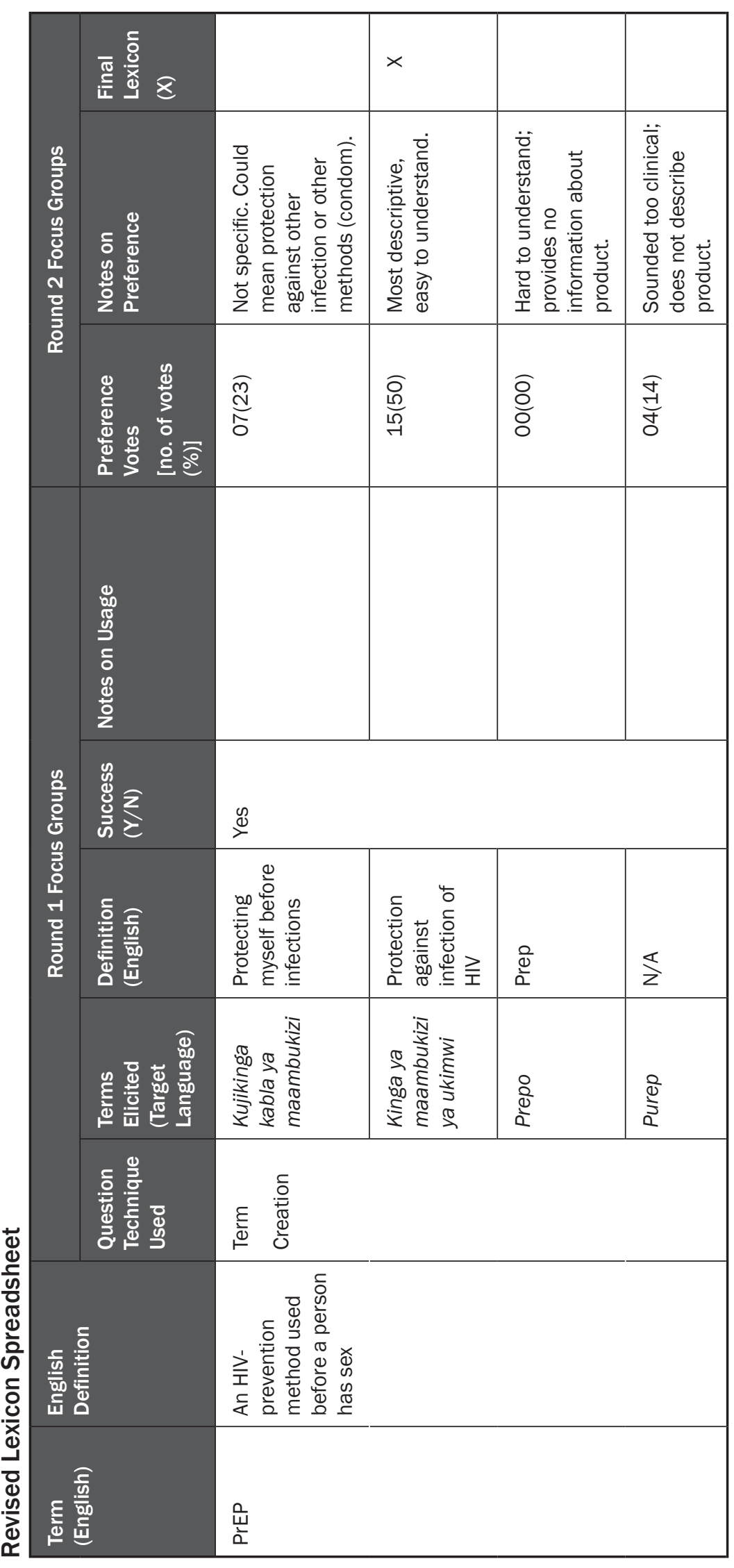




\section{APPENDIX 3. LEXICON EXAMPLE (SWAHILI)}

\begin{tabular}{|c|c|c|c|c|}
\hline 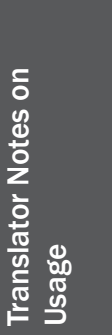 & 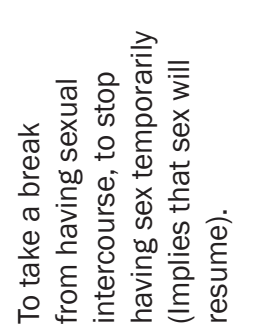 & 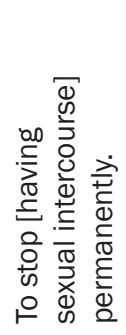 & 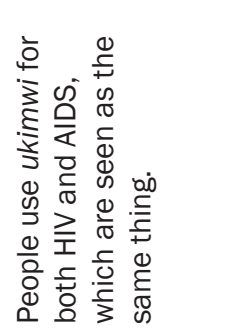 & 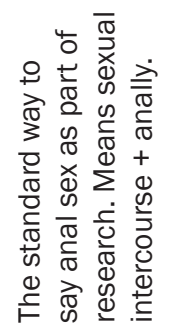 \\
\hline 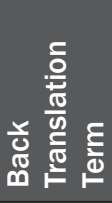 & 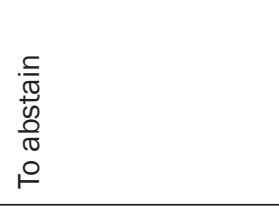 & $\begin{array}{l}\frac{5}{\sqrt[T]{\pi}} \\
\frac{0}{00} \\
\frac{0}{\pi} \\
\circ \\
\circ\end{array}$ & 号 & 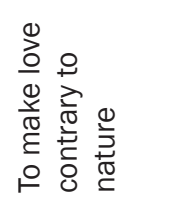 \\
\hline 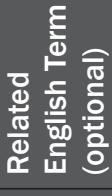 & & & & \\
\hline 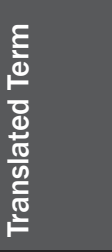 & $\begin{array}{l}\frac{0}{3} \\
: \sqrt[N]{3} \\
\frac{3}{3}\end{array}$ & \begin{tabular}{l}
$\frac{\pi}{\delta}$ \\
$\mathcal{J}$ \\
\multirow{2}{*}{}
\end{tabular} & : & 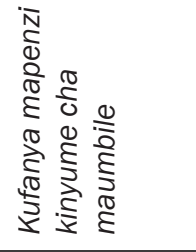 \\
\hline 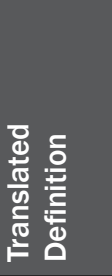 & 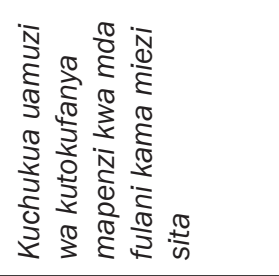 & & & 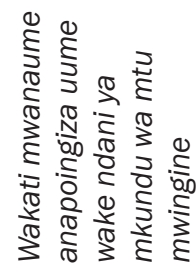 \\
\hline 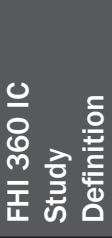 & 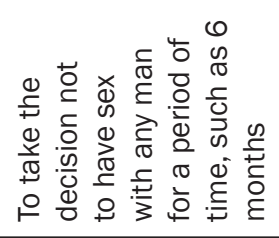 & & & 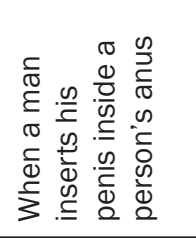 \\
\hline 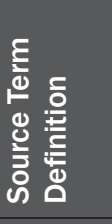 & & & 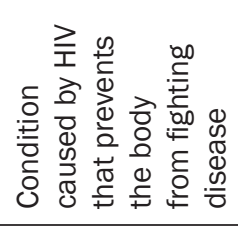 & 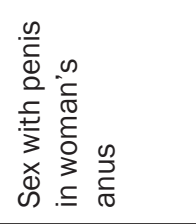 \\
\hline \& & $\begin{array}{l}\frac{5}{\pi} \\
\frac{\pi}{0} \\
\frac{0}{\pi} \\
\circ \\
\circ\end{array}$ & & 号 & 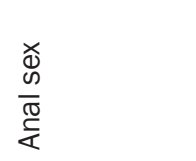 \\
\hline
\end{tabular}




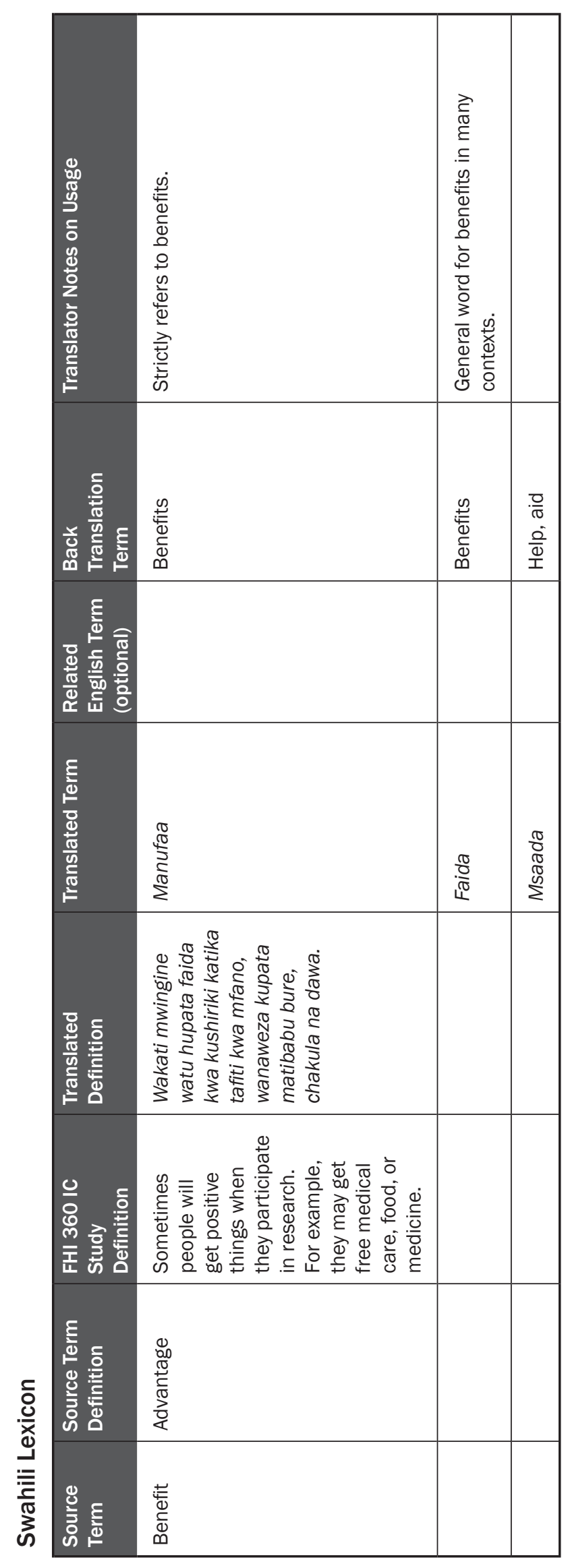




\begin{tabular}{|c|c|c|}
\hline 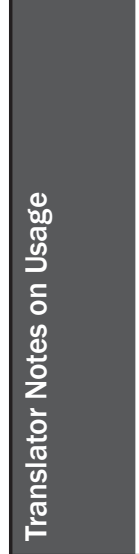 & 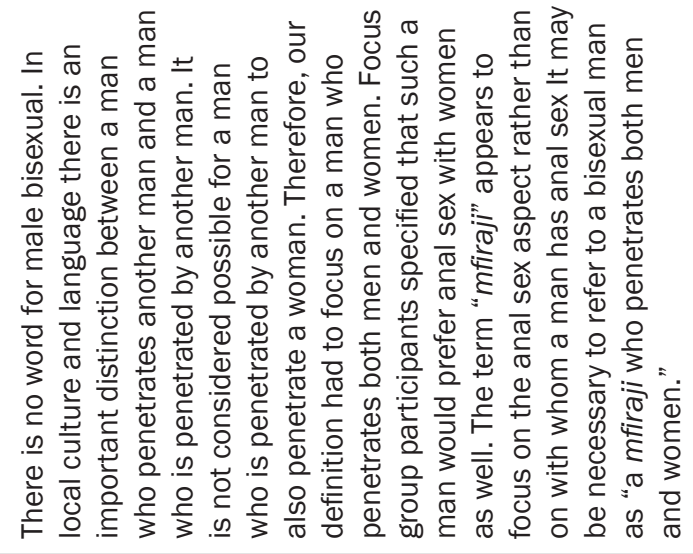 & 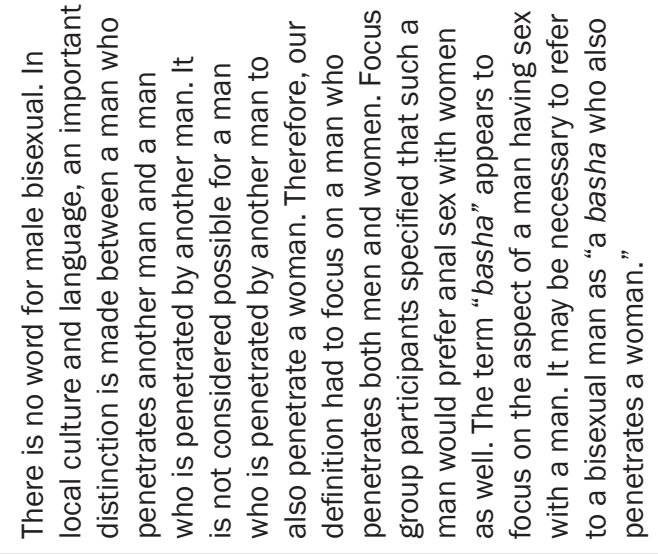 \\
\hline 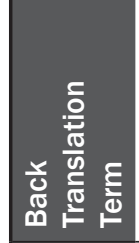 & 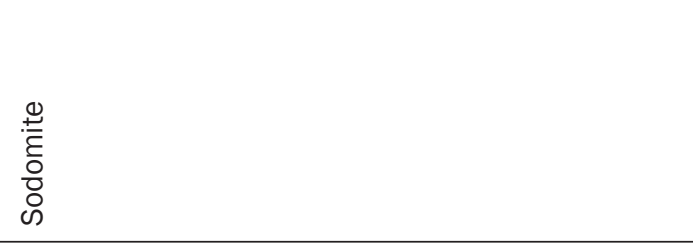 & 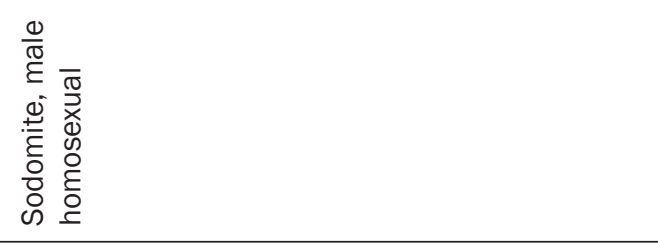 \\
\hline 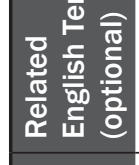 & & \\
\hline 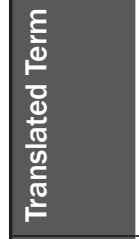 & 离 & $\begin{array}{l}\frac{0}{07} \\
0 \\
0\end{array}$ \\
\hline 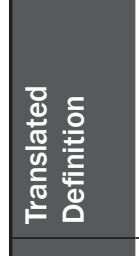 & 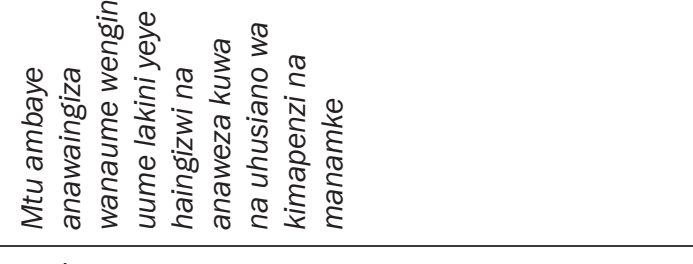 & \\
\hline 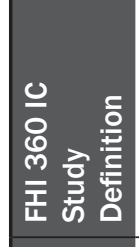 & 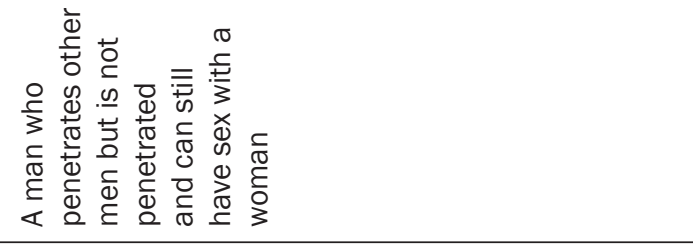 & \\
\hline 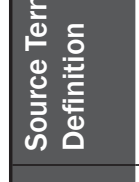 & & \\
\hline 导 & 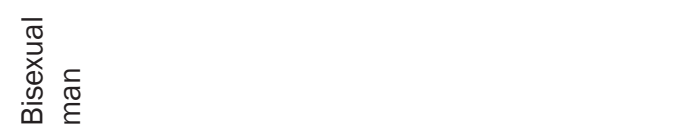 & \\
\hline
\end{tabular}




\begin{tabular}{|c|c|c|c|c|}
\hline 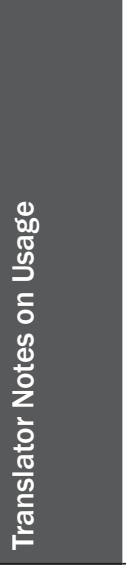 & & & 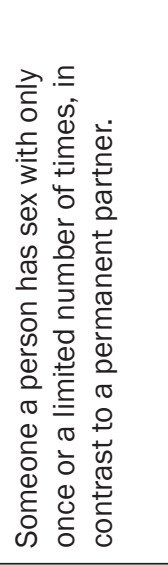 & 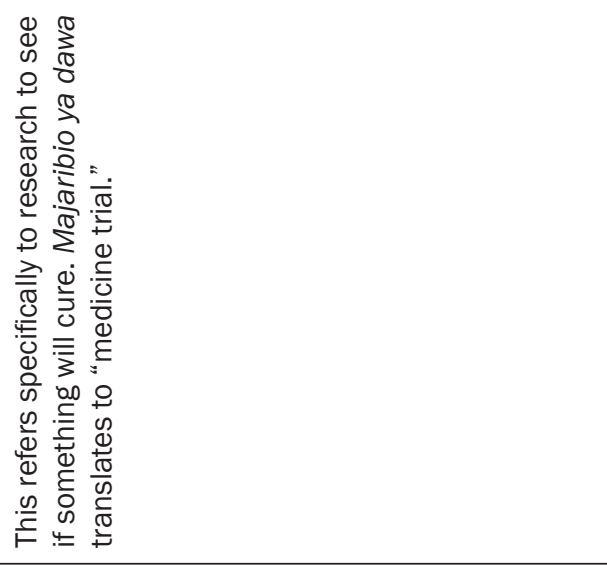 \\
\hline 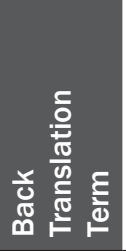 & 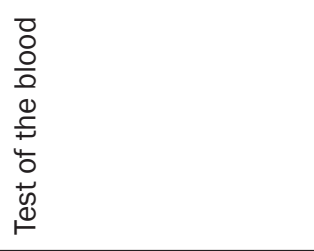 & 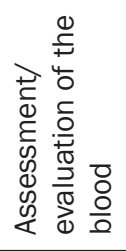 & 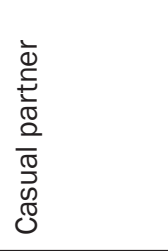 & 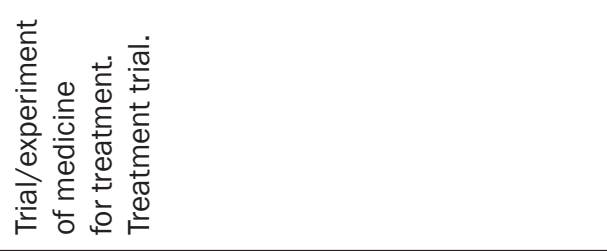 \\
\hline 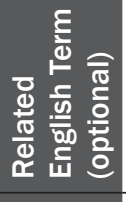 & & & & \\
\hline 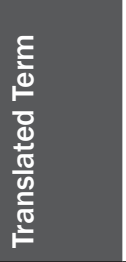 & 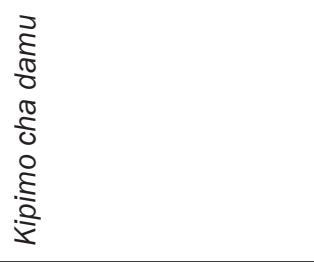 & 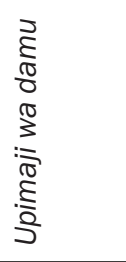 & 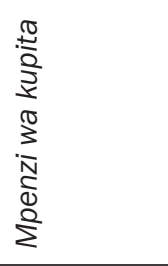 & 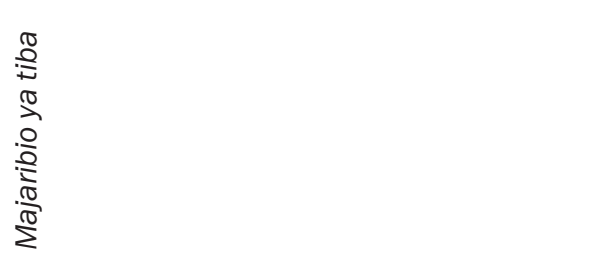 \\
\hline 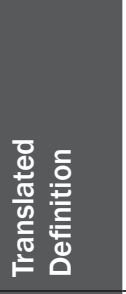 & 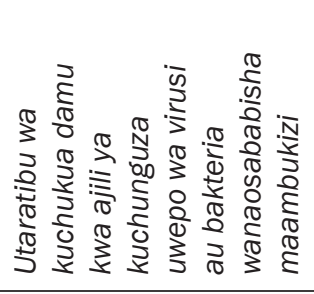 & & 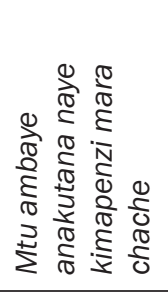 & 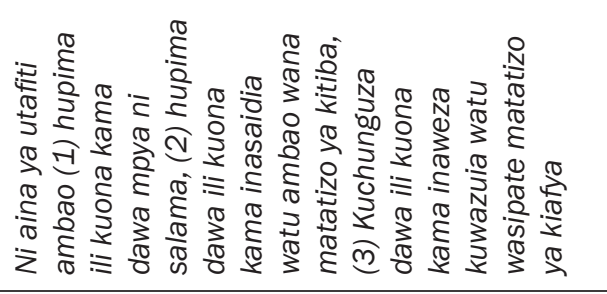 \\
\hline 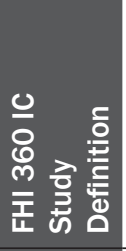 & 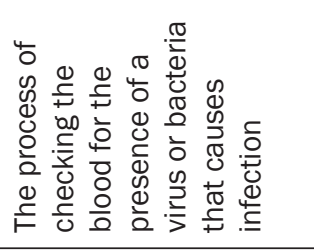 & & 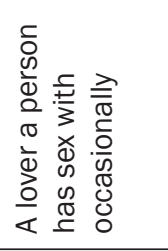 & 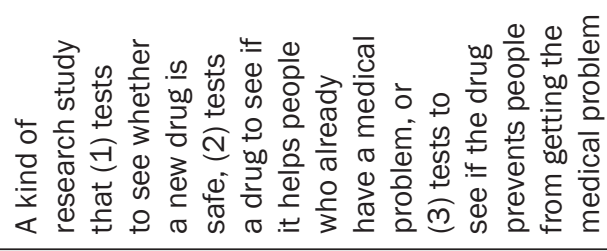 \\
\hline 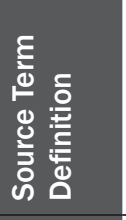 & 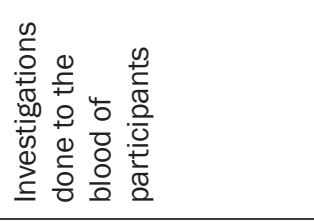 & & & 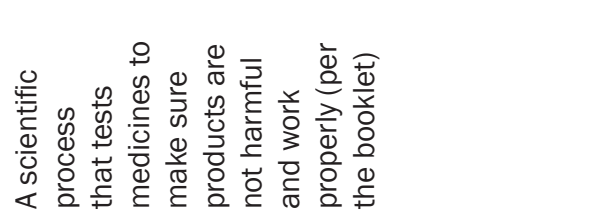 \\
\hline 递 & $\begin{array}{l}\frac{\ddot{W}}{\Phi} \\
\stackrel{+}{0} \\
\frac{0}{0}\end{array}$ & & 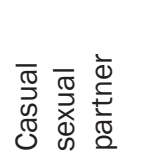 & 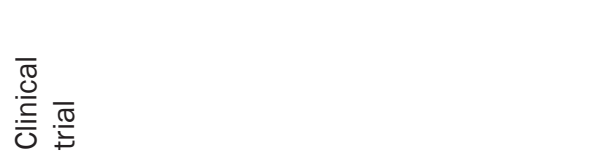 \\
\hline
\end{tabular}




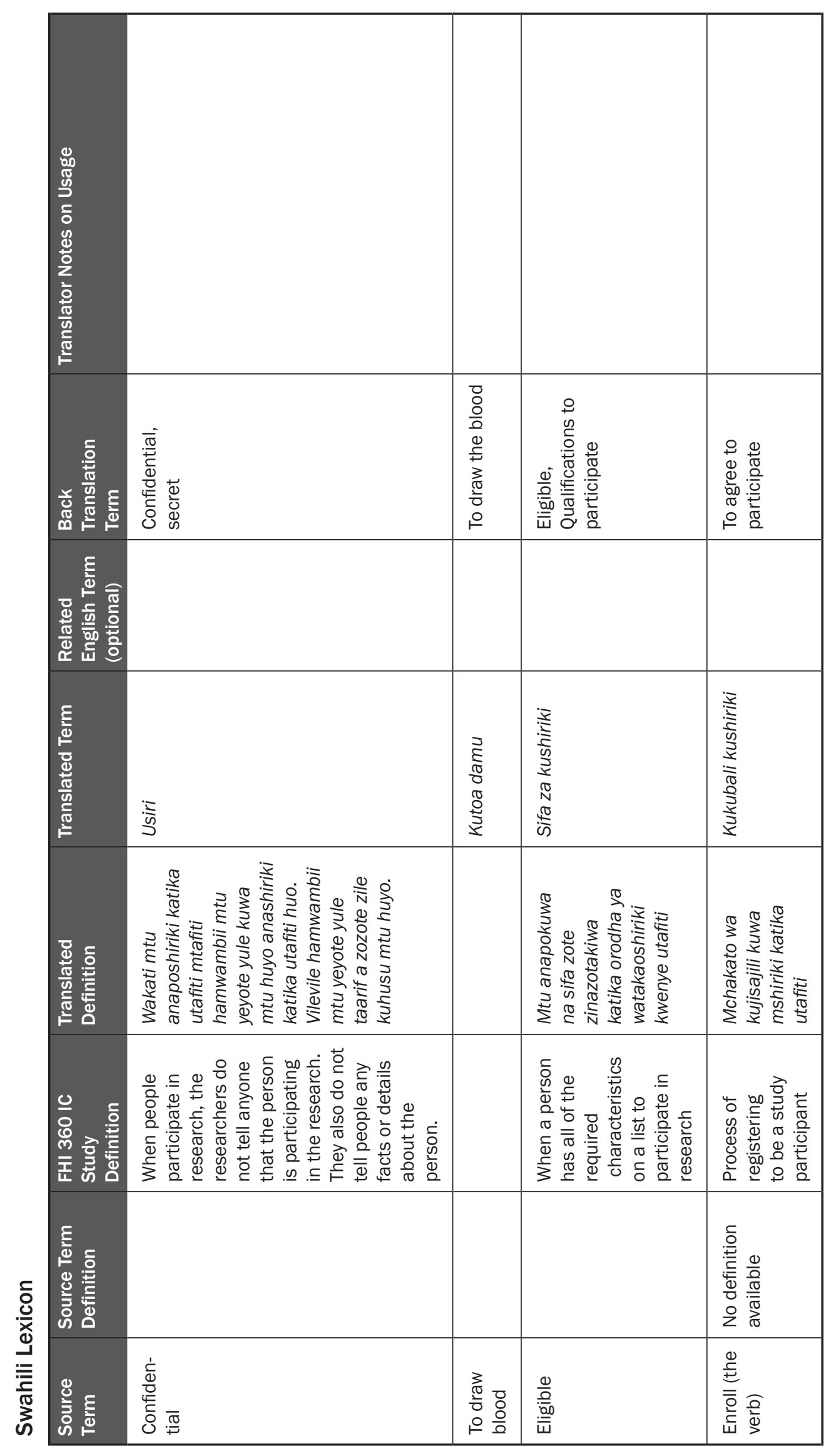




\begin{tabular}{|c|c|c|c|c|c|c|c|}
\hline 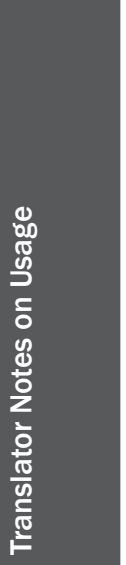 & & & & & 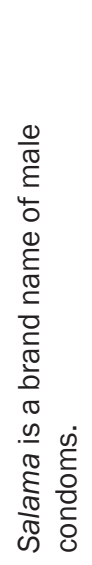 & 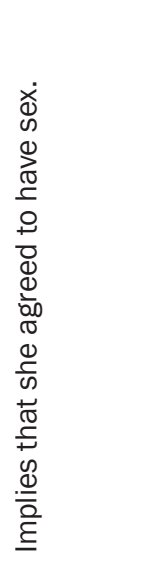 & 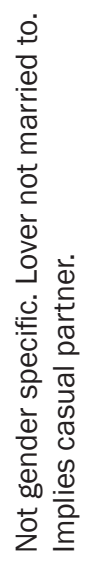 \\
\hline 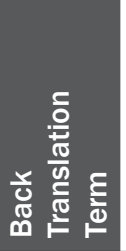 & 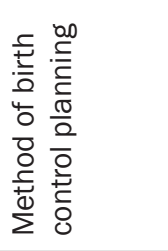 & 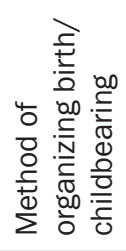 & 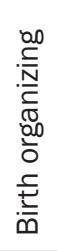 & 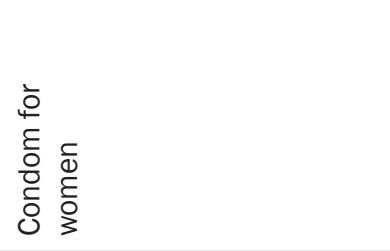 & 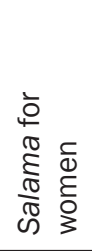 & 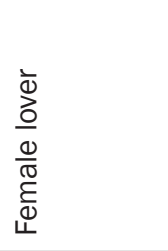 & 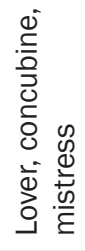 \\
\hline 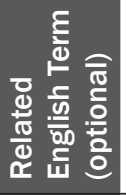 & & & & & & & \\
\hline 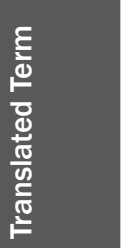 & 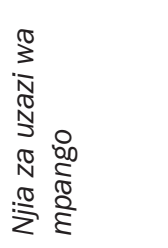 & 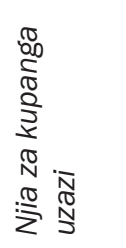 & 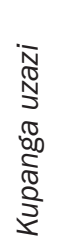 & 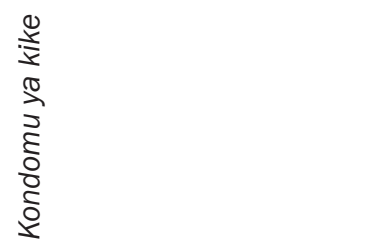 & 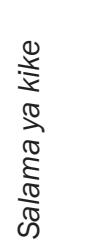 & 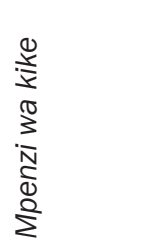 & $\begin{array}{l}\frac{\pi}{\pi} \\
\frac{\pi}{\pi} \\
\frac{\pi}{1}\end{array}$ \\
\hline 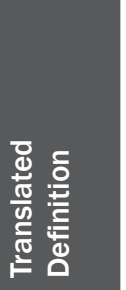 & 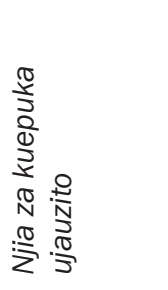 & & & 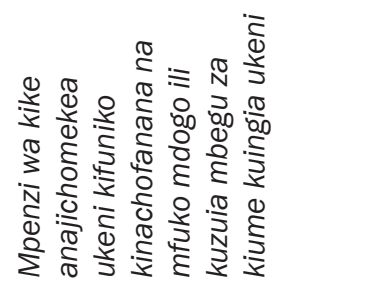 & & 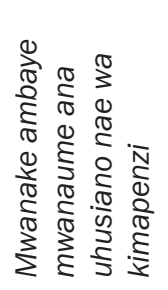 & \\
\hline 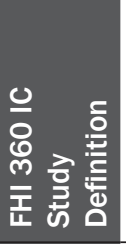 & 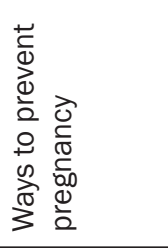 & & & 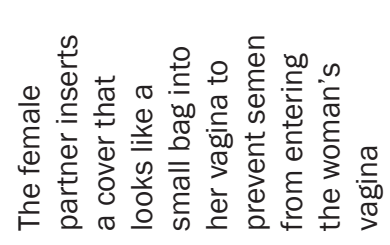 & & 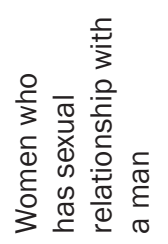 & \\
\hline 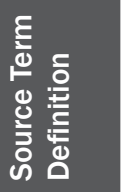 & 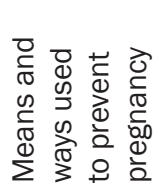 & & & 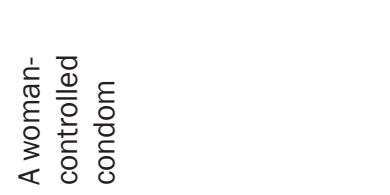 & & & \\
\hline 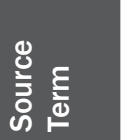 & 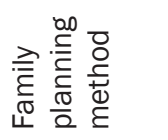 & & & 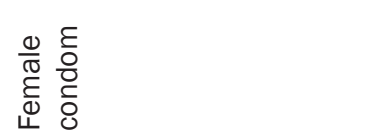 & & 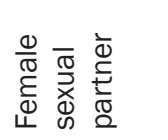 & \\
\hline
\end{tabular}




\begin{tabular}{|c|c|c|c|c|c|c|c|c|}
\hline 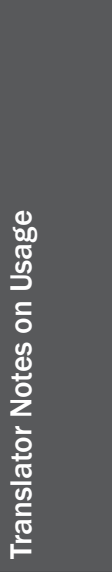 & & 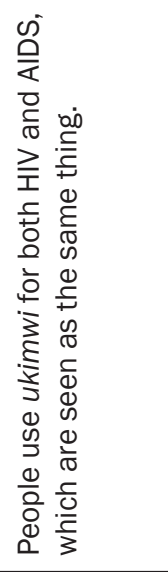 & & & 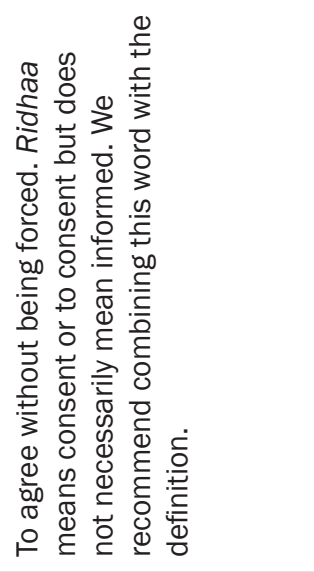 & & & 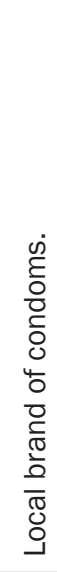 \\
\hline 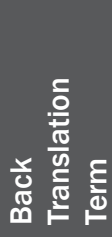 & 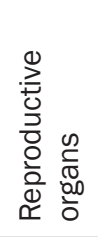 & 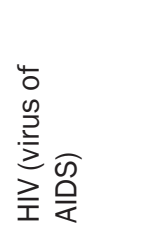 & 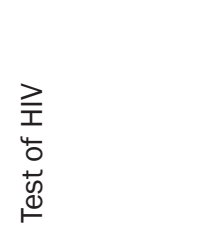 & $\begin{array}{l}\text { D } \\
\frac{0}{0} \\
\frac{0}{0} \\
\frac{0}{7} \\
\text { T⿱亠䒑 }\end{array}$ & 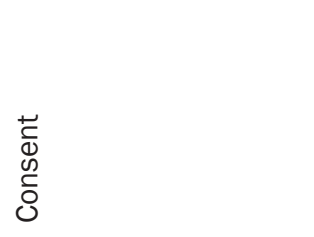 & $\begin{array}{l}\stackrel{n}{0} \\
.0 \\
\stackrel{0}{0} \\
\stackrel{\mathscr{N}}{\Xi}\end{array}$ & 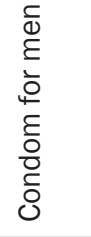 & $\underset{\infty}{\infty}$ \\
\hline 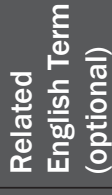 & & & & & & & & \\
\hline 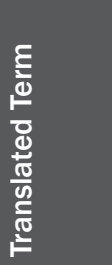 & 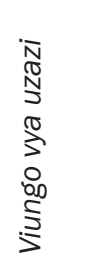 & 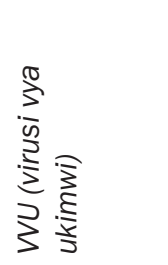 & 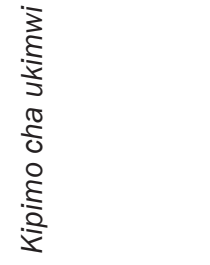 & 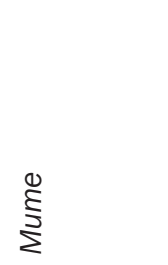 & $\begin{array}{l}\frac{\pi}{0} \\
\frac{\pi}{0} \\
\frac{0}{20}\end{array}$ & $\begin{array}{l}\frac{8}{\pi} \\
\frac{\pi}{0} \\
\stackrel{5}{\omega}\end{array}$ & 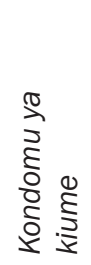 & $\frac{\tilde{\pi}}{\frac{\pi}{\pi}}$ \\
\hline 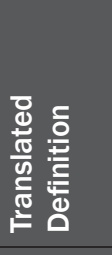 & & & 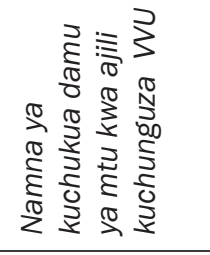 & & 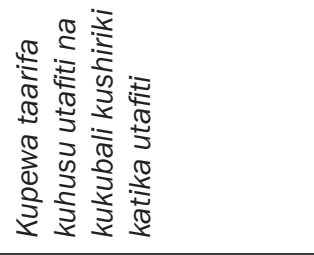 & & & \\
\hline 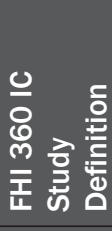 & & & 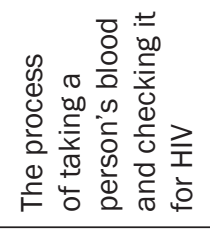 & & 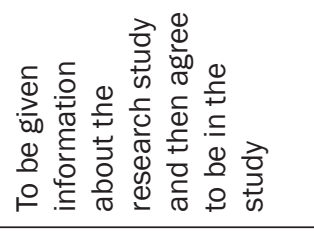 & & & \\
\hline 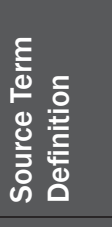 & 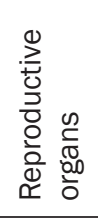 & 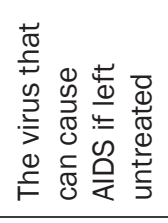 & & 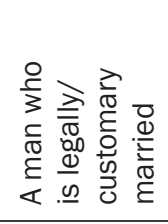 & 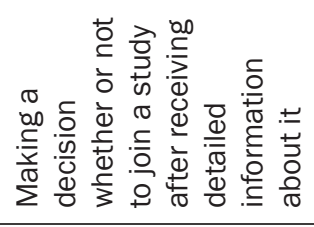 & & 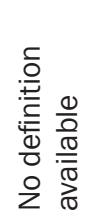 & \\
\hline ङ & 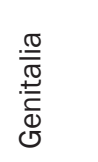 & 主 & 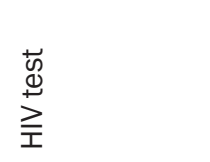 & $\begin{array}{l}\text { D } \\
\frac{1}{0} \\
00 \\
\frac{0}{0} \\
\text { I }\end{array}$ & 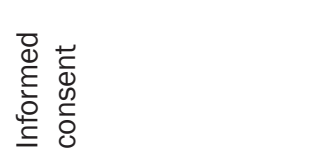 & $\begin{array}{l}0 \\
\frac{0}{0} \\
\frac{0}{0} \\
\stackrel{0}{0} \\
\stackrel{\mathscr{d}}{\Xi}\end{array}$ & 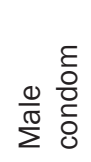 & \\
\hline
\end{tabular}




\begin{tabular}{|c|c|c|c|c|c|}
\hline 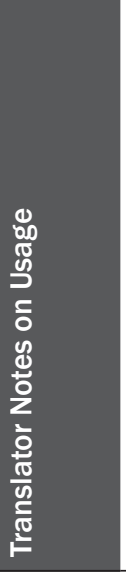 & 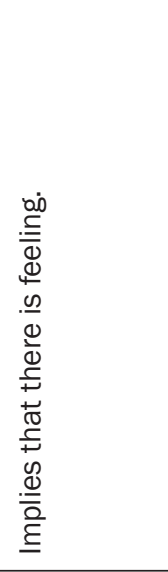 & 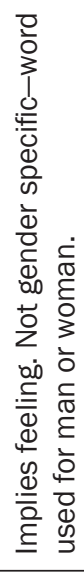 & 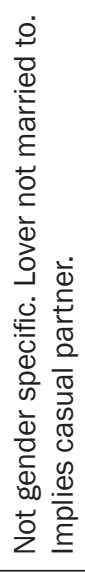 & & 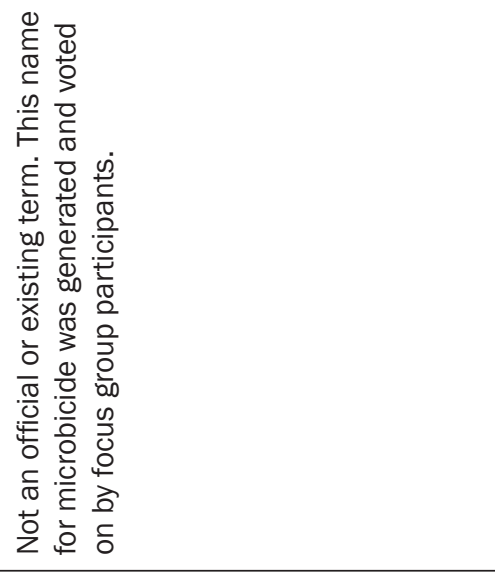 \\
\hline 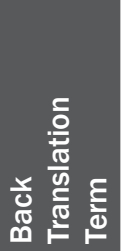 & 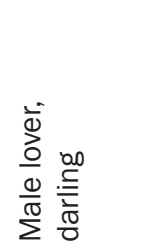 & 高 & 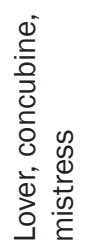 & 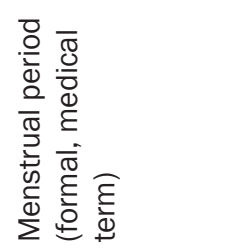 & 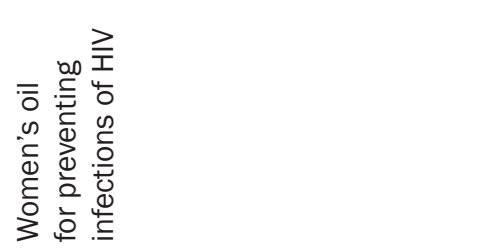 \\
\hline 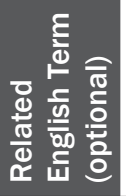 & & & & & \\
\hline 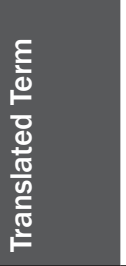 & 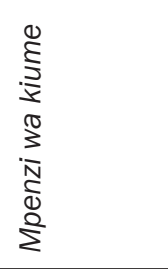 & $\begin{array}{l}\bar{N} \\
\frac{1}{\mathbb{N}} \\
\frac{2}{\Sigma}\end{array}$ & $\begin{array}{l}\frac{1}{\pi} \\
\frac{\pi}{\pi} \\
\frac{\pi}{\pi}\end{array}$ & $\begin{array}{l}\frac{i}{8} \\
\frac{d}{1}\end{array}$ & 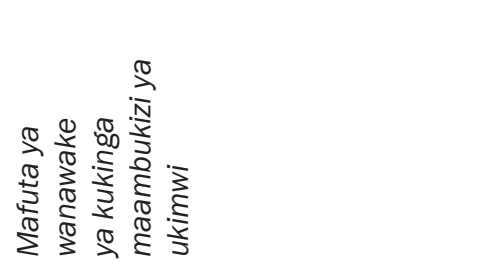 \\
\hline 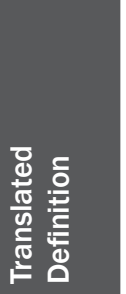 & 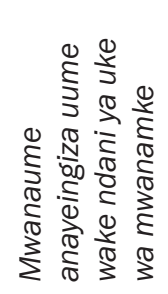 & & & 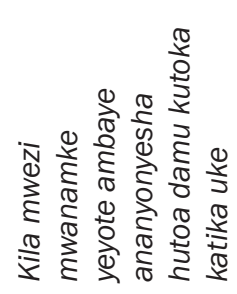 & 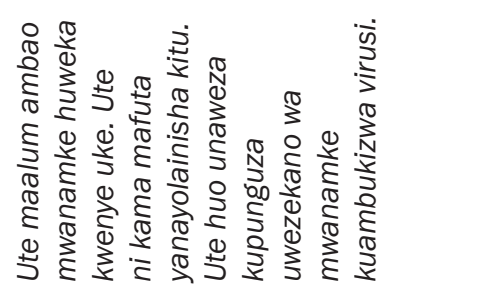 \\
\hline 을 & 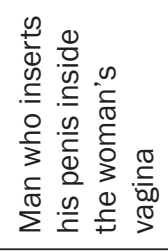 & & & 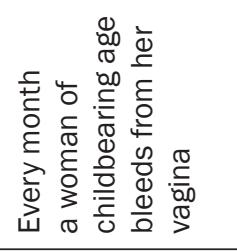 & 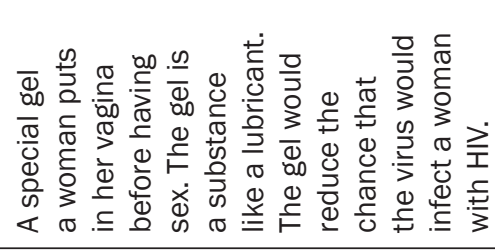 \\
\hline 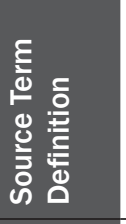 & & & & & 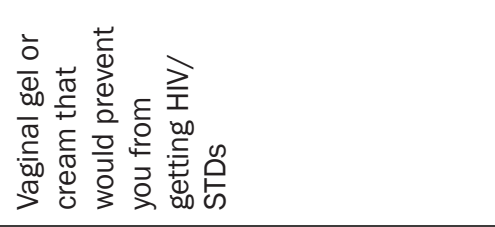 \\
\hline ฆ & 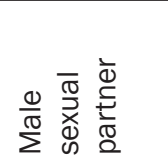 & & & 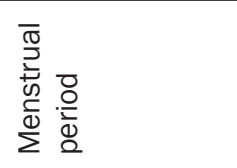 & $\frac{\frac{1}{\circ}}{\frac{0}{0}} \frac{0}{\frac{0}{2}}$ \\
\hline
\end{tabular}




\begin{tabular}{|c|c|c|c|c|}
\hline 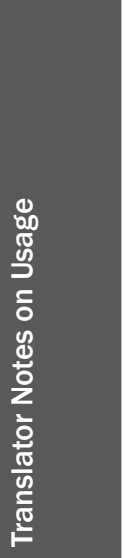 & 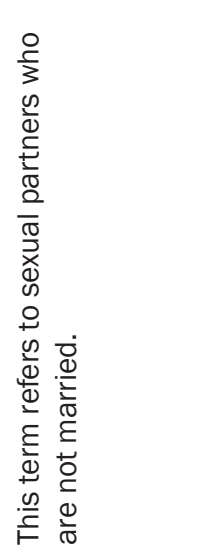 & 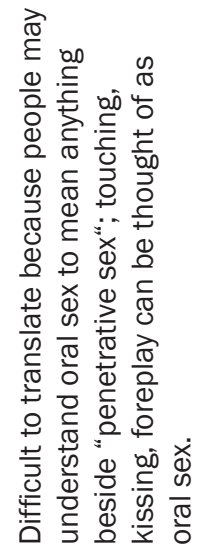 & & \\
\hline 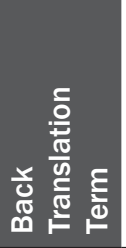 & $\begin{array}{l}\frac{\grave{D}}{\partial} \\
\underline{0} \\
\stackrel{0}{0}\end{array}$ & 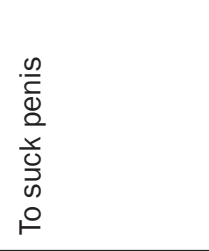 & 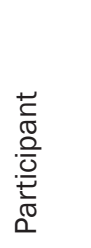 & 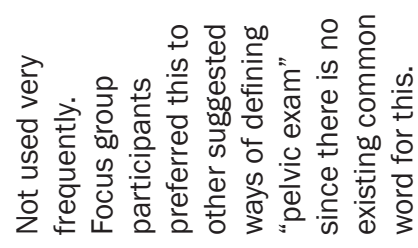 \\
\hline 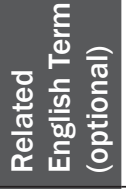 & & & & \\
\hline 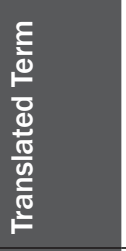 & 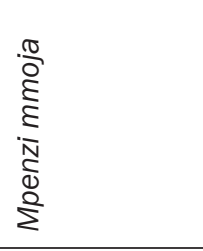 & 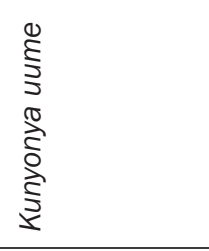 & 竞 & 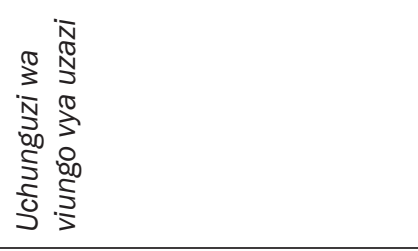 \\
\hline 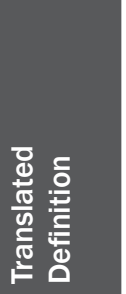 & 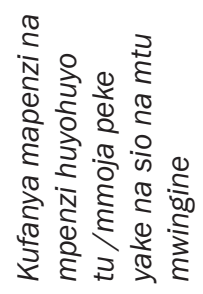 & 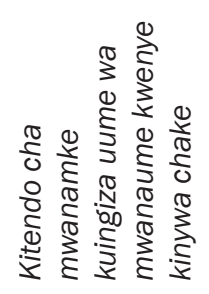 & & 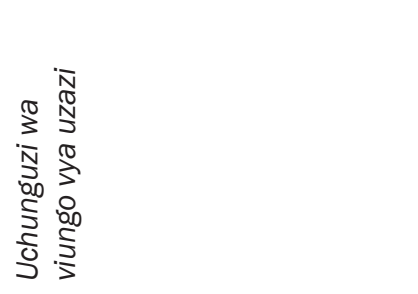 \\
\hline 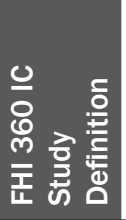 & 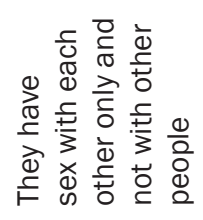 & 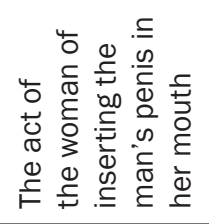 & & 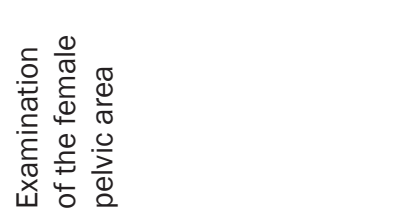 \\
\hline 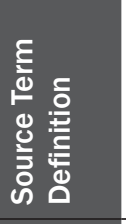 & & & 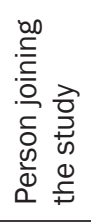 & 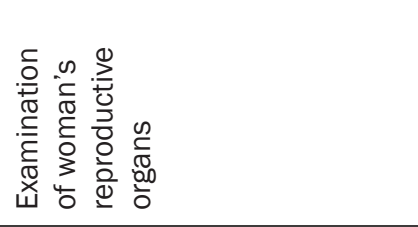 \\
\hline 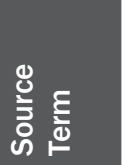 & 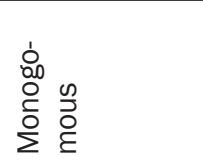 & 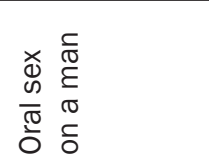 & 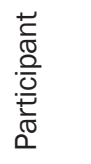 & 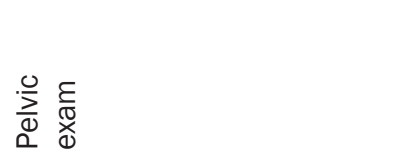 \\
\hline
\end{tabular}




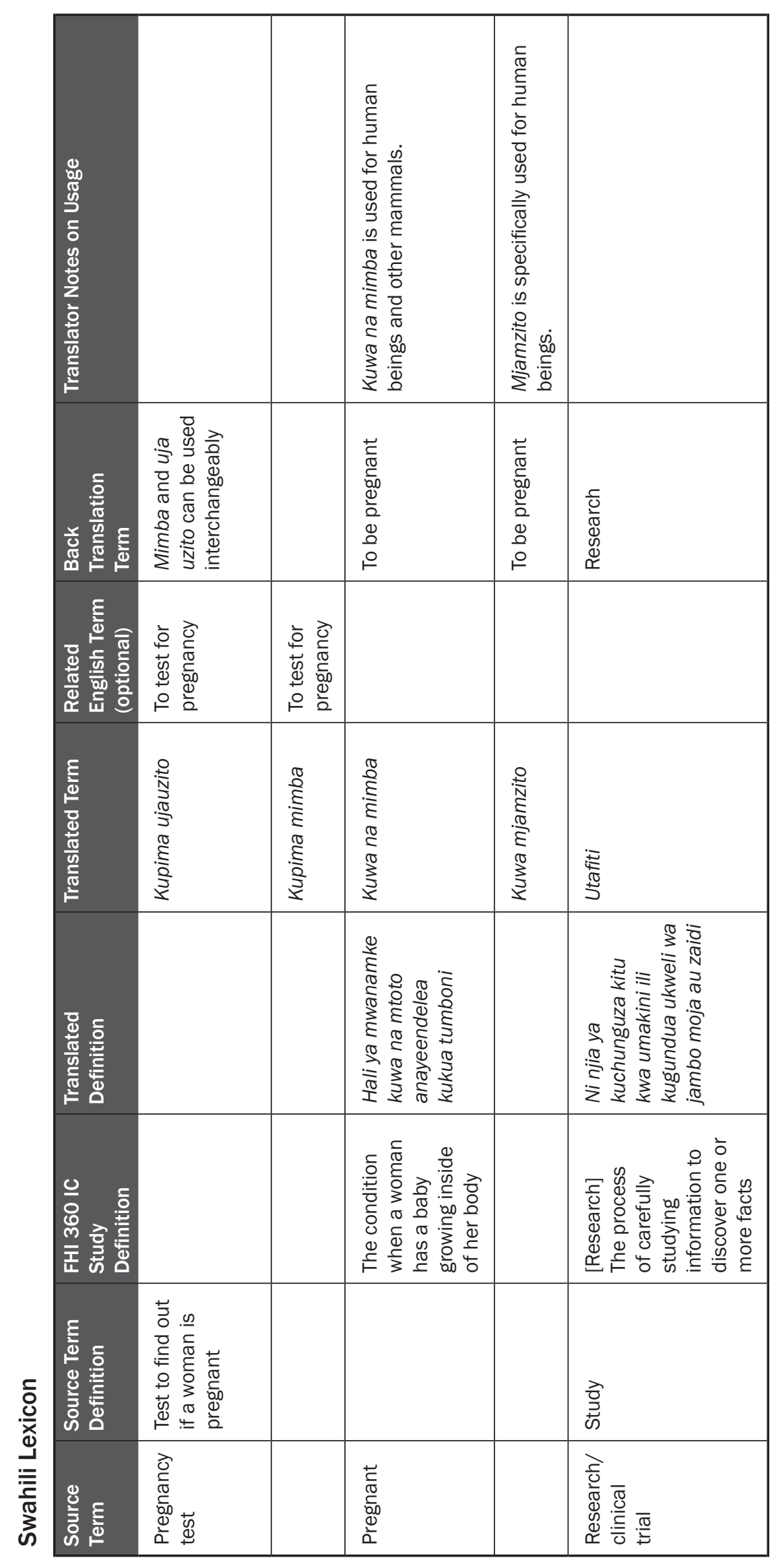




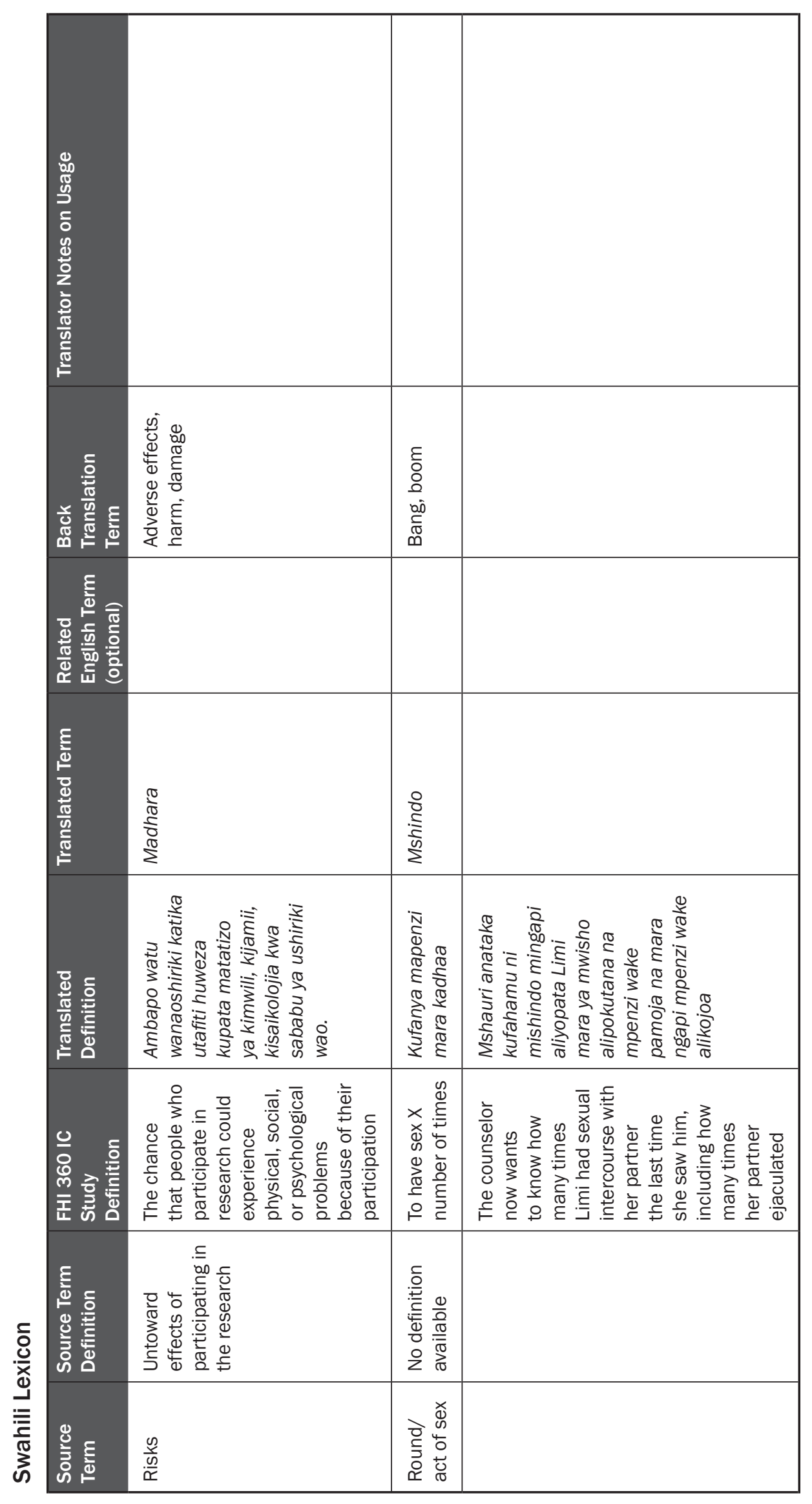




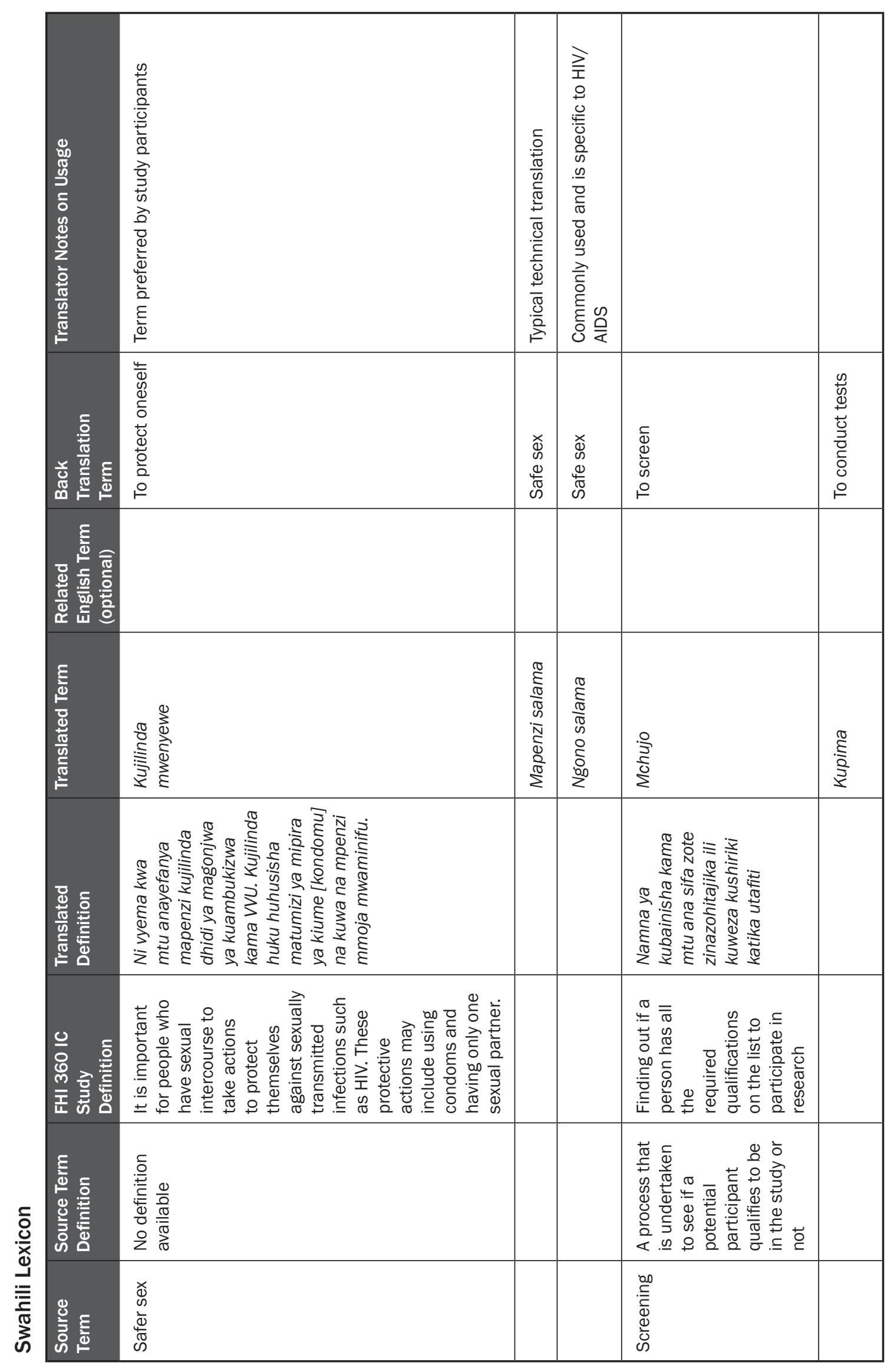




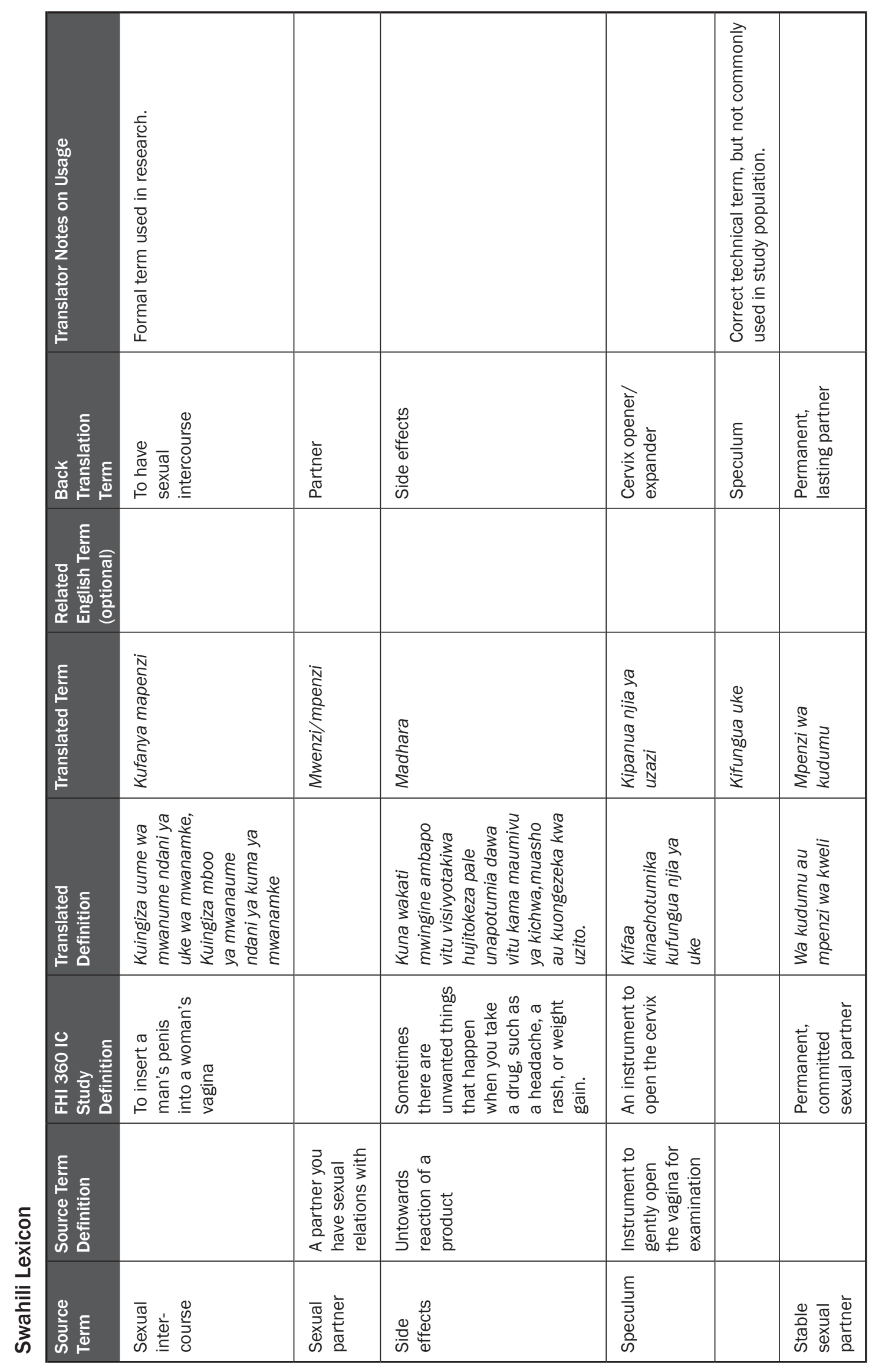




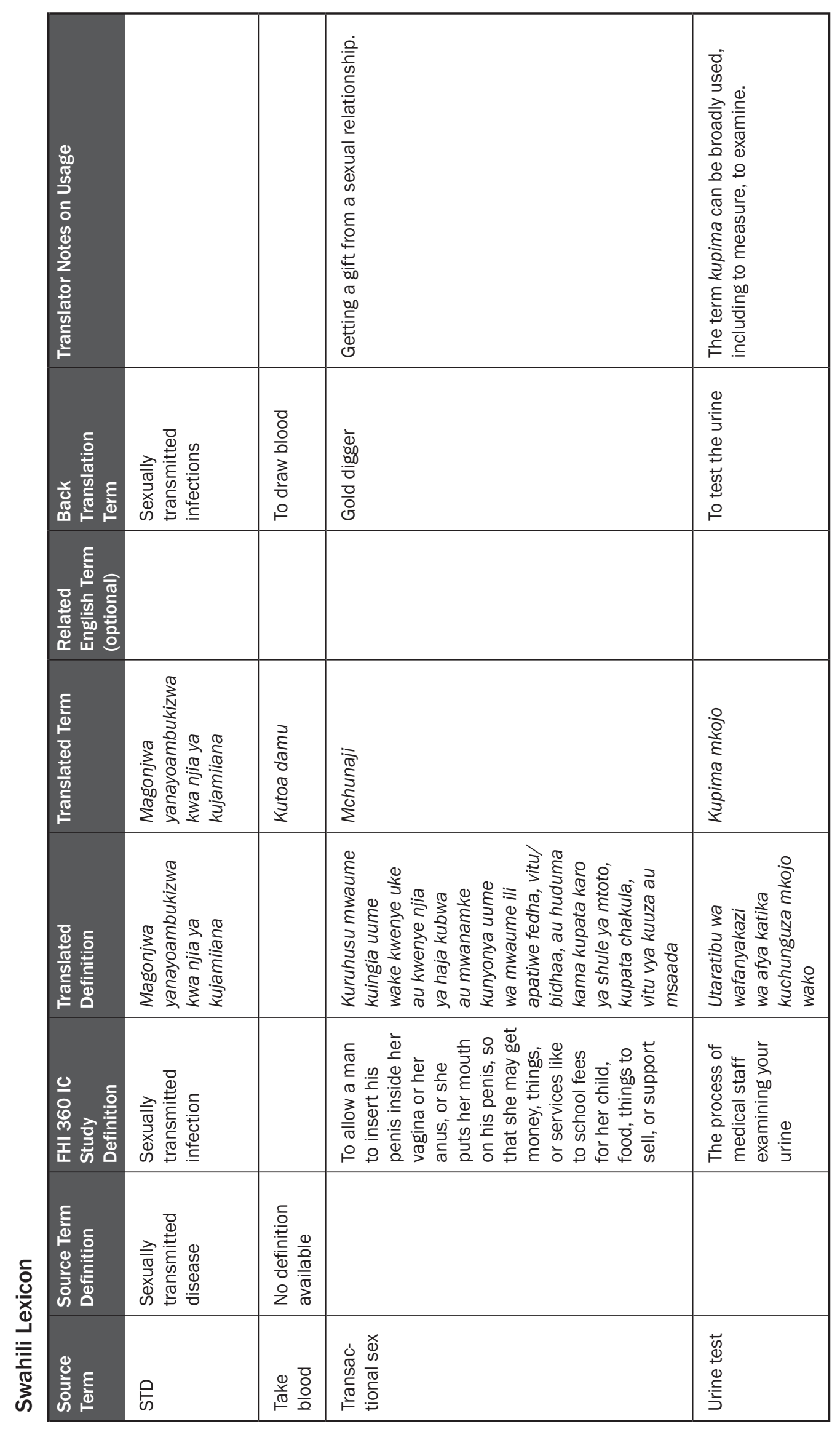




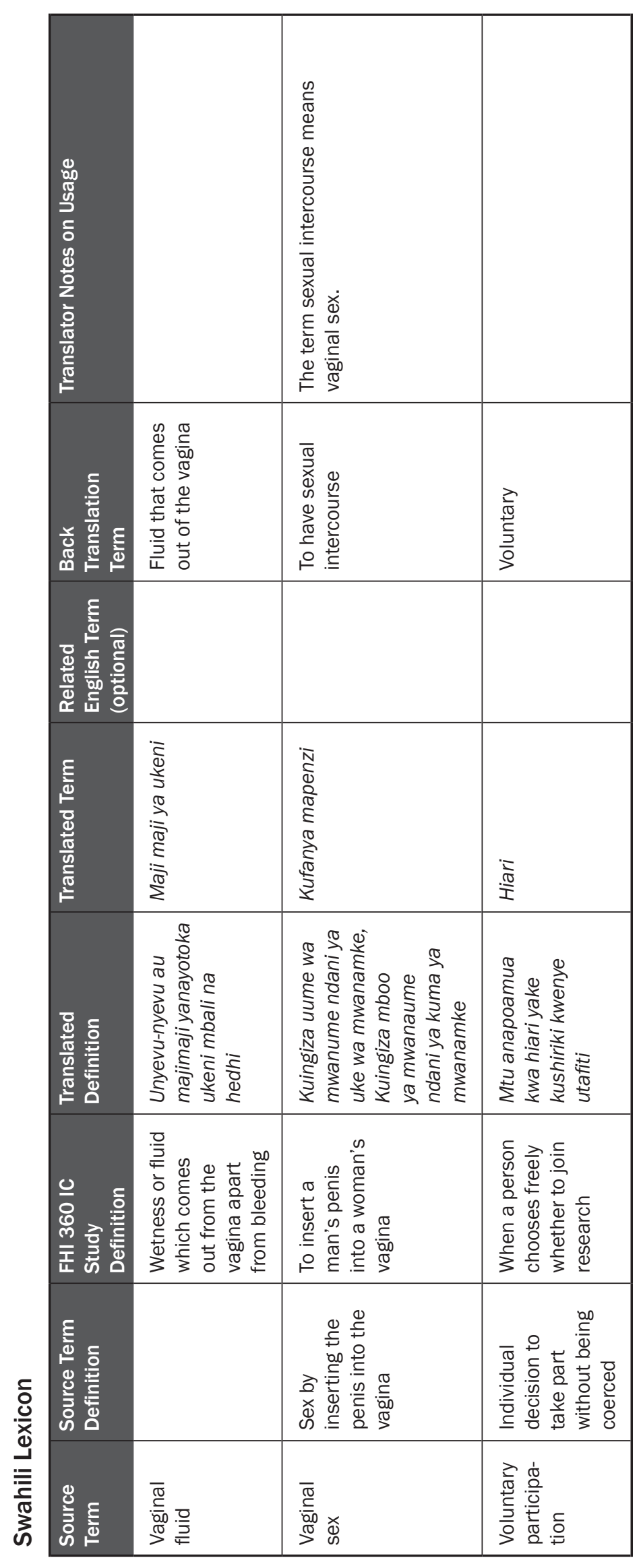




\section{APPENDIX 4. LEXICON DATABASE SAMPLE SCREENS}

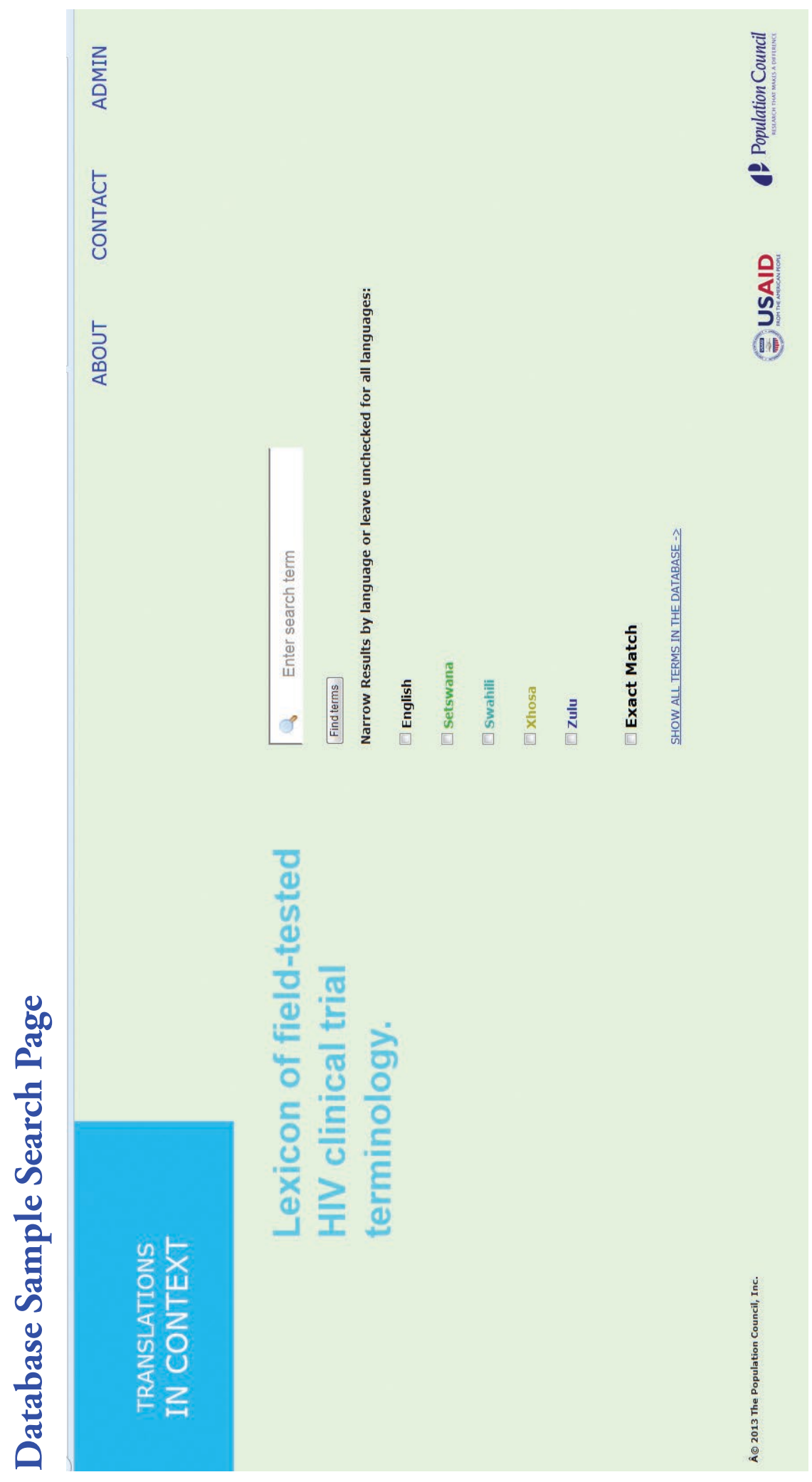




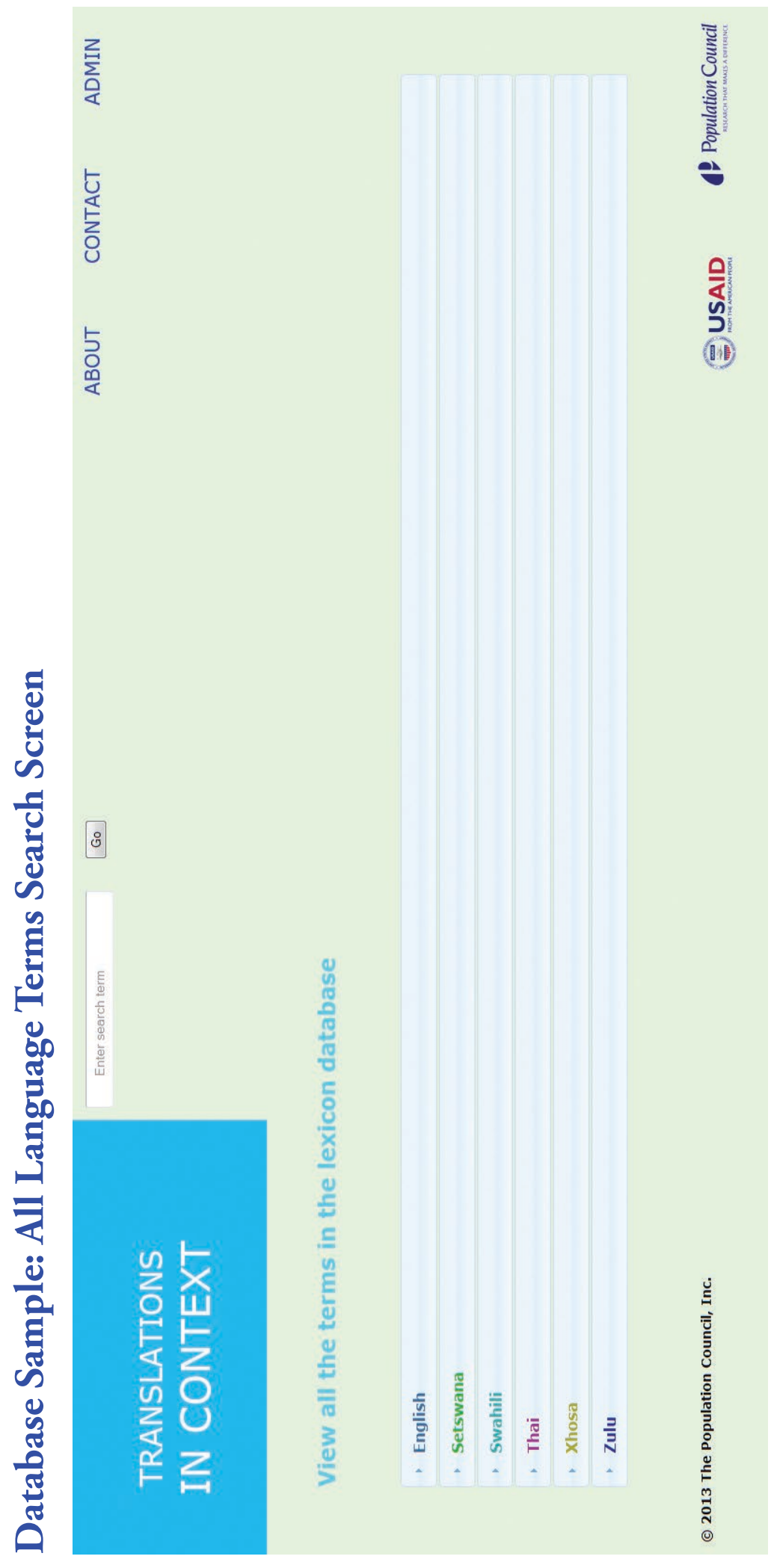




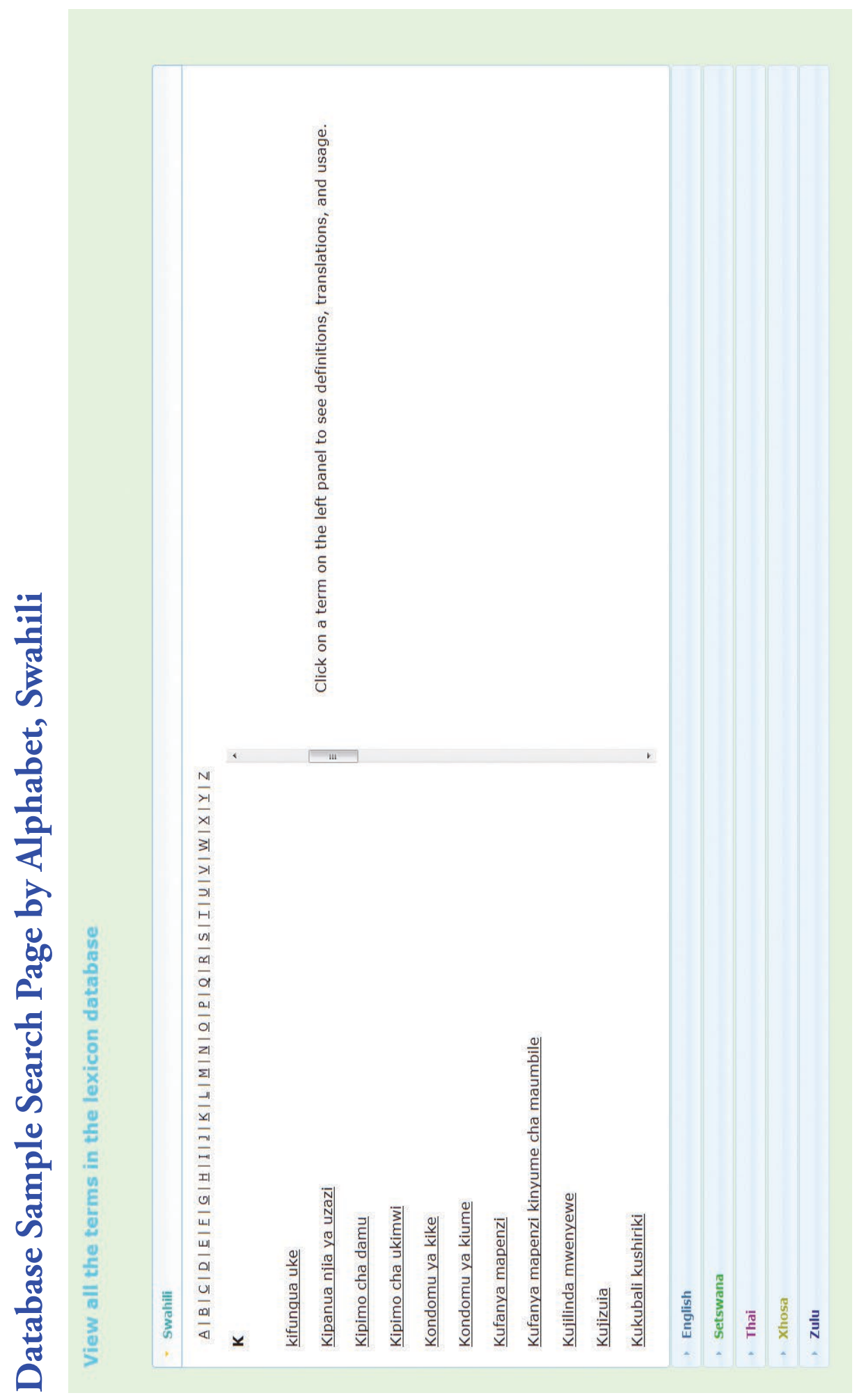

A Toolkit for Developing Bilingual Lexicons for International HIV Prevention Clinical Trials a 61 


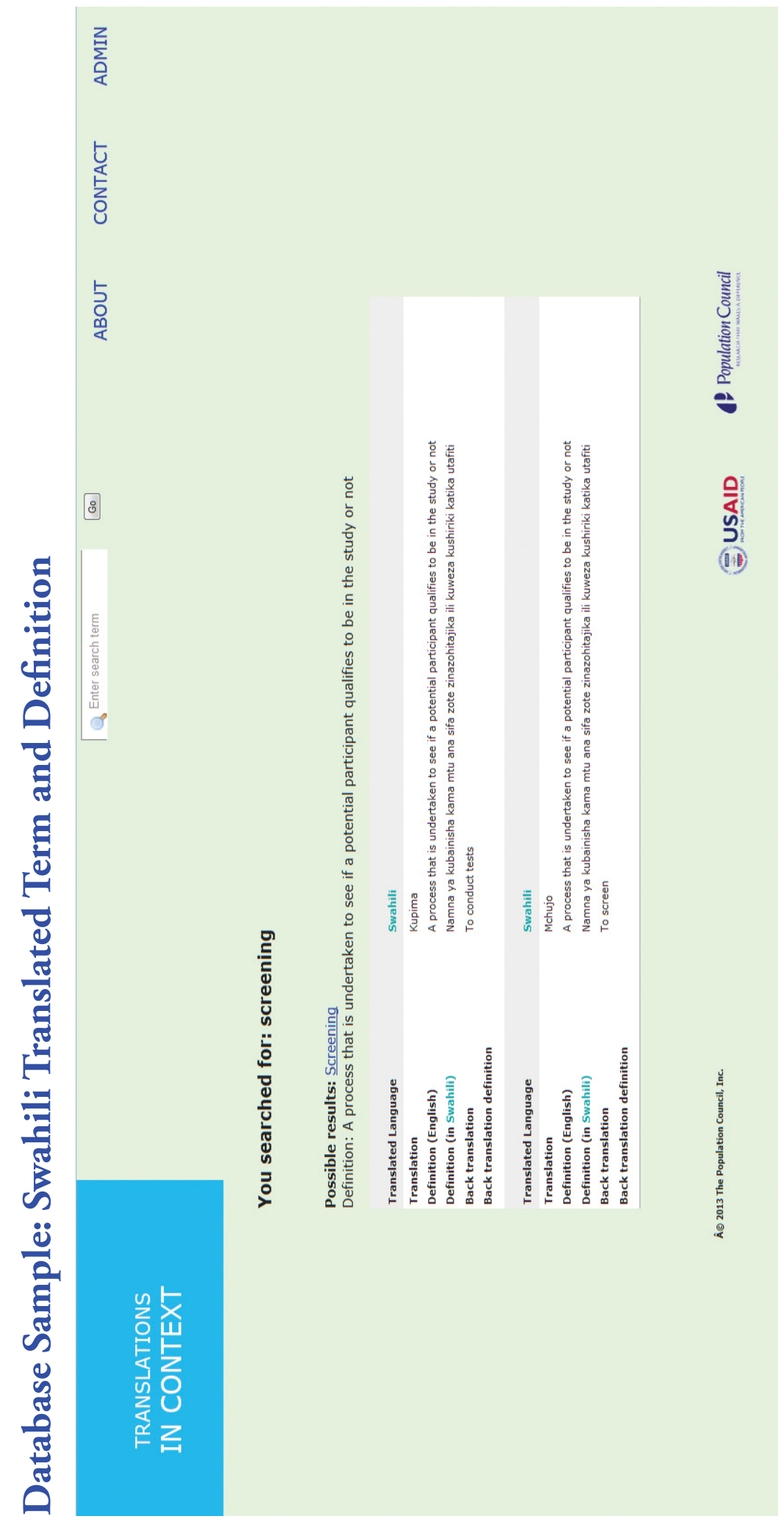



Population Council

One Dag Hammarskjold Plaza

9th Floor

New York, New York 10017 USA

www.popcouncil.org 